\title{
Potential impacts from biological aerosols on ensembles of continental clouds simulated numerically
}

\author{
V. T. J. Phillips ${ }^{1}$, C. Andronache ${ }^{2}$, B. Christner ${ }^{3}$, C. E. Morris ${ }^{4}$, D. C. Sands ${ }^{5}$, A. Bansemer ${ }^{6}$, A. Lauer $^{7}$, \\ C. McNaughton ${ }^{8}$, and C. Seman ${ }^{9}$ \\ ${ }^{1}$ Department of Meteorology, University of Hawaii at Manoa, Honolulu, USA \\ ${ }^{2}$ Boston College, Chestnut Hill, Massachusetts, USA \\ ${ }^{3}$ Department of Biological Sciences, Louisiana State University, Baton Rouge, Louisiana, USA \\ ${ }^{4}$ INRA, Unité de Pathologie Végétale UR407, 84140 Montfavet, France \\ ${ }^{5}$ Plant Sciences and Plant Pathology, Montana State University, Montana, USA \\ ${ }^{6}$ National Center for Atmospheric Research (NCAR), Boulder, Colorado, USA \\ ${ }^{7}$ International Pacific Research Center (IPRC), University of Hawaii at Manoa, Honolulu, USA \\ ${ }^{8}$ Department of Oceanography, University of Hawaii at Manoa, Honolulu, USA \\ ${ }^{9}$ Geophysical Fluid Dynamics Laboratory (GFDL), Princeton, New Jersey, USA
}

Received: 18 January 2008 - Published in Biogeosciences Discuss.: 4 March 2008

Revised: 22 April 2009 - Accepted: 20 May 2009 - Published: 12 June 2009

\begin{abstract}
An aerosol-cloud modeling framework is described to simulate the activation of ice particles and droplets by biological aerosol particles, such as airborne icenucleation active (INA) bacteria. It includes the empirical parameterisation of heterogeneous ice nucleation and a semi-prognostic aerosol component, which have been incorporated into a cloud-system resolving model (CSRM) with double-moment bulk microphysics. The formation of cloud liquid by soluble material coated on these partially insoluble organic aerosols is represented. It determines their partial removal from deep convective clouds by accretion onto precipitation in the cloud model. This "aerosol-cloud model" is validated for diverse cases of deep convection with contrasting aerosol conditions, against satellite, ground-based and aircraft observations.

Simulations are performed with the aerosol-cloud model for a month-long period of summertime convective activity over Oklahoma. It includes three cases of continental deep convection simulated previously by Phillips and Donner (2006). Elevated concentrations of insoluble organic aerosol, boosted by a factor of 100 beyond their usual values for this continental region, are found to influence significantly the following quantities: (1) the average numbers and sizes of ice crystals and droplets in the clouds; (2) the horizontal cloud coverage in the free troposphere; (3) pre-
\end{abstract}

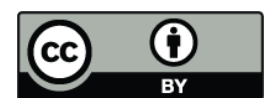

Correspondence to: V. T. J. Phillips (vaughanp@hawaii.edu) cipitation at the ground; and (4) incident solar insolation at the surface. This factor of 100 is plausible for natural fluctuations of the concentration of insoluble organic aerosol, in view of variability of cell concentrations for airborne bacteria seen by Lindemann et al. (1982).

In nature, such boosting of the insoluble organic aerosol loading could arise from enhanced emissions of biological aerosol particles from a land surface. Surface wetness and solar insolation at the ground are meteorological quantities known to influence rates of growth of certain biological particles (e.g. bacteria). Their rates of emission into the atmosphere must depend on these same quantities, in addition to surface wind speed, turbulence and convection. Finally, the present study is the first attempt at evaluating the impacts from biological aerosols on mesoscale cloud ensembles in the literature.

\section{Introduction}

Throughout the atmosphere, clouds are a major control on the fluxes of solar and infrared radiation that drive the climate system. Any cloud is a vast set of aerosols $(<1 \mu \mathrm{m}$ in size usually) made very visible by becoming cloud droplets or ice crystals $(>1 \mu \mathrm{m})$ in saturated conditions (the process of "activation" or "nucleation"). The concentrations and chemical composition of aerosols, and the ascent-dependent supersaturation, all determine how many activate. Numbers of

Published by Copernicus Publications on behalf of the European Geosciences Union. 
cloud particles then determine their average size, which in turn governs cloud radiative (Twomey, 1959, 1977) and microphysical (e.g. Khain et al., 2004; Khain and Pokrovsky, 2004; Phillips et al., 2001, 2002, 2003, 2005, 2007) properties, as well as cloud life-time (Albrecht, 1989) and spatial extent (see also Ming et al., 2007). In this way, aerosols influence climate (e.g. Lohmann et al., 1999; Lohmann and Feichter, 2005; Forster et al., 2007).

The interaction between aerosols and glaciated clouds is particularly uncertain (Forster et al., 2007), as reviewed by Lohmann and Feichter (2005). Between 0 and $-36^{\circ} \mathrm{C}$ (the "mixed-phase region"), liquid water can be supercooled and cloud droplets ("cloud liquid") can co-exist with ice crystals ("cloud ice"), with sufficient ascent. Above the mixed-phase region, clouds consist only of ice. Certain insoluble aerosols can heterogeneously nucleate ice crystals, acting as ice nuclei (IN) at sub-zero temperatures and high enough humidities.

"Homogeneous freezing" is ice nucleation without the action of IN aerosols at cold levels above the mixed-phase region. Rime-splintering at temperatures between -3 and $-8^{\circ} \mathrm{C}$ yields extra ice crystals by the "Hallett-Mossop (HM) process" (Hallett and Mossop, 1974) of ice particle multiplication. In warm or mixed-phase clouds, some soluble aerosols activate to become cloud droplets, acting as cloud condensation nuclei $(\mathrm{CCN})$.

Primary biological aerosol particles (PBAPs) are emitted from land sources into the troposphere and are ubiquitous (Jaenicke, 2005). They include pollen, bacteria, fungal spores, viruses, plant and animal fragments (e.g. Despres et al., 2007). PBAPs co-exist with many other species of aerosol, comprising about $25 \%$ of all aerosols larger than $0.2 \mu \mathrm{m}$ (Jaenicke, 2005). The smaller PBAPs at sub-micron sizes are seen to be the most numerous (Matthias-Maser and Jaenicke, 1995). If PBAPs become coated with soluble material (or if their surface is wet-able), they can act as CCN and activate as cloud droplets (e.g. Möhler et al., 2007).

PBAPs have insoluble components, such as the cellwall/membrane of bacteria, and can sometimes act as IN, nucleating ice. Most ice crystals nucleated heterogeneously in the troposphere are formed on IN of dust and insoluble carbonaceous aerosol (e.g. DeMott et al., 2003a). Some of the latter are organic (e.g. Targino et al., 2007). If they are the insoluble components of PBAPs, their precise biological origin is not yet clear.

Ice-nucleation active (INA) bacteria (e.g. Vali et al., 1976; Lindow et al., 1978; as reviewed by Morris et al., 2004), leaf litter (Schnell and Vali, 1972, 1976) and pollen (Diehl et al., 2001; Diehl and Wurzler, 2004) are PBAPs that can sometimes nucleate ice (e.g. Möhler et al., 2007; Morris et al., 2008b). In freshly fallen snow, biogenic nucleators of ice are present at concentrations of up to about 500 particles per litre of melted snow at about $-10^{\circ} \mathrm{C}$, many of them being sensitive to "lysozyme" (enzymes that damage cell-walls of bacteria), being of bacterial origin (Christner et al., 2008). The relatively warm activity of these IN imply they have a "phe- notype" (an observable characteristic of an organism) which enhances their ice nucleating capabilities.

Aircraft observations from the Ice in Clouds Experiment Layer-clouds (ICE-L) from Wyoming in 2007 reveal that biological particles (either bacteria or plant matter) are present in the residual material from heterogeneously nucleated ice crystals at a frequency (about $30 \%$ of residual particles on average) that varies greatly (Pratt et al., 2009). They were positively identified as having mass spectral signatures known from laboratory studies to be biological. It is likely that some participated in nucleating the crystals in which they were found.

Airborne INA bacteria were selected as partially representative of insoluble organic IN, for construction of an "empirical parameterisation" of heterogeneous ice nucleation (Phillips et al., 2008). In the Mid-West of the USA (North and South Dakota, Wisconsin, Kansas) Pseudomonas (P.) syringae has been a plant disease seen to afflict fields of wheat and barley, especially in the early growing season (Caristi et al., 1991). $P$. syringae is a species of INA bacteria and often becomes airborne (e.g. Lindemann et al., 1982). Its concentration was seen to be highly variable (Sect. 5.1).

Most micro-organisms known to be ice nucleators are plant-associated (see Morris et al., 2004). There is evidence that vegetated land masses are the principle origin of biological ice nucleators in the atmosphere at some geographical locations (e.g. Christner et al., 2008). Meteorological conditions near the land surface determine sources there of icenucleating PBAPs, such as airborne INA bacteria, in several ways. For instance, bacterial growth rates on leaf surfaces can depend on the length of time a leaf stays wet after rain or dew, and on the air temperature (e.g. Caristi et al., 1991). Wind speed is a factor, too. Thus, a feedback exists between rainfall and emissions of bacteria from the biosphere, if they then activate and modify cloud properties (Sands et al., 1982). This possibility partly motivates the present study.

Cloud processes are represented by "bulk microphysics schemes" within cloud-system resolving models (CSRMs). The most advanced bulk schemes predict the numbers of cloud droplets and ice crystals, as well as their masses, allowing their mean sizes to be predicted. Such schemes are referred to as "double-moment" (e.g. Morrison et al., 2005; Phillips et al., 2007).

In the present study, an observed period of continental deep convection in Oklahoma is simulated with an aerosolcloud model. It occurred over the Southern Great Plains (SGP) site in Oklahoma as part of the Atmospheric Radiation and Measurement (ARM) campaign during summer (ARM-SGP-1997; 19 June-17 July 1997). The ARM-SGP1997 campaign has been selected as it is where high variability of the concentration of ice-nucleating PBAPs is possible in the atmosphere (Sect. 3). The model is a CSRM with a double-moment representation of clouds and a semiprognostic aerosol component. It predicts the (bi-directional) aerosol-cloud-radiation interaction in a two-way sense with 
6 chemical species of aerosol. It represents the nucleation of both ice crystals and cloud droplets by insoluble organic aerosols (internally mixed with soluble material), such as PBAPs.

The overall aim of the present study is to examine the influence, from plausible changes in loadings of insoluble organic aerosol, on mesoscale ensembles of simulated continental clouds over Oklahoma. Impacts on meteorological conditions in their vicinity are assessed. Such changes in insoluble organic aerosol could be produced in nature by enhanced emissions of biological aerosols over the land surface. These would include ice-nucleating particles, like leaf litter or airborne INA bacteria. Diehl et al. (2006) simulated biological ice nucleation in a single cloudy parcel. However, the present study is the first attempt at evaluating the impacts from biological material on cloud ensembles that we are aware of, in the literature.

In the next two Sections, the aerosol-cloud model and experimental design are described. In Sect. 4, its control simulation of continental convection in Oklahoma (ARM-SGP1997) is compared with satellite, ground-based and aircraft observations. Subsequent sections show and discuss results from sensitivity tests using the control run, exploring effects from extra insoluble organic aerosols on cloud ensembles.

\section{Description of the numerical model of the aerosol- cloud-radiation interaction}

\subsection{Overview}

The model applied in the present study is a CSRM. Its development was started by Phillips and Donner (2006) within the general framework of the Weather, Research and Forecasting (WRF) model. CSRMs simulate ensembles of clouds of many types. Double-moment bulk microphysics with interactive radiation was incorporated into the CSRM by Phillips et al. (2007). Predicted number concentrations constrain mean sizes of cloud droplets and of ice crystals, which then determine both their average fall-speeds and the radiative properties of clouds simulated by the CSRM, as described by Phillips et al. (2007).

More recently, the CSRM has been upgraded to include a semi-prognostic aerosol component for diverse chemical species of aerosol. It now predicts the depletion of environmental aerosols in various species as they activate to become cloud-particles that are then removed by accretion onto precipitation ("in-cloud nucleation/precipitation scavenging"). Equally, it treats the replenishment of environmental aerosols when cloud and precipitation either evaporates or sublimes away. The concentrations and chemical composition of a variety of aerosol species now determine the numbers of cloud droplets and ice crystals activated, in terms of their $\mathrm{CCN}$ and IN activity. Insoluble organic aerosols, a group that includes airborne INA bacteria, form one such species.
A novel empirical parameterisation is described in detail by Phillips et al. (2008). It predicts the known and quantified modes of heterogeneous nucleation of ice from the loadings and size distributions of multiple chemical species of insoluble (e.g. organic) aerosol. It has been implemented with treatment of in-cloud nucleation/precipitation scavenging, as outlined by Phillips et al. (2008).

\subsection{Semi-prognostic aerosol component}

\subsubsection{Aerosol chemical composition and size distribu- tions}

The semi-prognostic aerosol component includes 3 soluble and 3 insoluble chemical species of aerosol:

- ammonium sulphate;

- sea-salt (sub-micron only);

- soluble organic carbonaceous;

- mineral dust/metallic;

- soot;

- insoluble organic carbonaceous (e.g. biological).

Prognostic variables (Sect. 2.2.2) for the mixing ratios of these species' mass and particle number are advected and diffused like other variables in the CSRM. Aerosol size distributions are assumed to be lognormal with either one or two modes for each species.

Tables 1 and 2 list values of parameters of lognormal modes for all aerosol size distributions in the cloud model, being prescribed according to tropospheric observations for continental and maritime conditions. Aircraft data over eastern North America were collected during the first Intercontinental Chemical Transport Experiments (INTEX-NA) (Clarke et al., 2004). Data over the remote eastern North Pacific were collected during previous campaigns (Clarke and Kapustin, 2002) and the second INTEX experiment (INTEX-B) (McNaughton, 2008). Sea-salt and sulphate soluble aerosols are assumed to be externally mixed with one another, following Ming et al. (2006, 2007), while soluble organic material is internally mixed with sulphate. Insoluble aerosol species are assumed to be externally mixed with each other, but internally mixed with prescribed mass fractions of soluble material (sulphate) of 0.15 and 0.8 for dust and carbonaceous species respectively (Phillips et al., 2008), in view of field observations (e.g. Clarke et al., 2004). (This soluble mass fraction of 0.8 was observed for insoluble carbonaceous aerosol material, probably not biological, in a pollution plume. The soluble mass fraction of biological aerosols must vary widely in nature, depending on their age and proximity to land sources, and may be as low as 0.1 even. Its value prescribed here $(0.8)$ may be viewed as an upper limit on the real average value for remote continental aerosol conditions. 
Table 1. Parameters governing the log-normal size distributions of aerosol for continental aerosol conditions (bimodal in general for dust, sulphate and soluble organics; monomodal otherwise). They are the geometric mean diameters $\left(D_{g, X}\right)$, standard deviation ratios $\left(\sigma_{X}\right)$, and bulk density $\left(\rho_{X}\right)$ for aerosols in group $X$, where $X$ is a label denoting sulphate $\left(\mathrm{SO}_{4}\right)$, sea-salt (SS), soluble organic (solO), dust/metallic $(\mathrm{DM})$, black carbon $(\mathrm{BC})$ and insoluble organic $(\mathrm{O})$ aerosols, respectively. All aerosol sizes are specified here in terms of equivalent spherical diameter. For dust and sulphate, total particle numbers in both modes (Pruppacher and Klett, 1997, Eqs. (8-43) therein) are shown. For sulphate, the parameter values are based on aircraft data from INTEX-NA over land and from the Pacific described by McNaughton et al. (2008; "M08"). Some data for sea-salt are from Clarke et al. (2006; "C06"). Some are from Ming et al. (2006; "Mi06"). Data for carbonaceous aerosol is from Matthias-Maser and Jaenicke (1995; "MJ95") and Clarke et al. (2004, 2007; "C04", "C07"), with various other papers for dust as listed by Phillips et al. (2008; "P08"). The height of the boundary layer, $H_{b l}$, was assumed to be $2 \mathrm{~km}$. The total number concentration of particles in each mode is denoted by $n_{l, X}$, where $l$ is 1 or 2 labelling the mode. Units of $z$ and $H_{b l}$ are km. Values for sulphate aerosol are held constant in the upper troposphere at their values at 9 and $12 \mathrm{~km}$ altitude over land and ocean respectively above these levels.

\begin{tabular}{|c|c|c|}
\hline Symbol & Value & Origin \\
\hline$n_{1, \mathrm{DM}}: n_{2, D M}$ & 150:1 & P08 \\
\hline$n_{1, \mathrm{SO}_{4}}: n_{2, \mathrm{SO}_{4}}\left(9>z>H_{b l}\right)$ & $170 \exp \left[\left(z-H_{b l}\right) / 2.4\right]: 1000 \exp \left[-\left(z-H_{b l}\right) / 10.0\right]$ & M08(INTEX-NA) \\
\hline$n_{2, \mathrm{SO}_{4}}\left(z<H_{b l}\right)$ & 0 & M08 (INTEX-NA) \\
\hline$n_{1, \mathrm{solO}}: n_{2, \mathrm{solO}}$ & $n_{1, \mathrm{SO}_{4}}: n_{2, \mathrm{SO}_{4}}$ & M08 \\
\hline$D_{g, \mathrm{SO}_{4}}\left(1 \mathrm{st}\right.$ mode, $\left.9>z>H_{b l}\right)$ & $0.04 \exp \left[-\left(z-H_{b l}\right) / 10\right] \mu \mathrm{m}$ & M08 (INTEX-NA) \\
\hline$D_{g, \mathrm{SO}_{4}}\left(2\right.$ nd mode, $\left.9>z>H_{b l}\right)$ & $0.08 \exp \left[-\left(z-H_{b l}\right) / 15\right] \mu \mathrm{m}$ & M08 (INTEX-NA) \\
\hline$D_{g, \mathrm{SO}_{4}}\left(z<H_{b l}\right)$ & $0.05 \mu \mathrm{m}$ & M08 (INTEX-NA) \\
\hline$D_{g, \mathrm{SS}}$ & $0.5 \mu \mathrm{m}$ & M08, C06 \\
\hline$D_{g, \text { solO }}$ & $D_{g, \mathrm{SO}_{4}}$ & M08 \\
\hline$D_{g, \mathrm{DM}}(1 \mathrm{st}$ mode $)$ & $0.8 \mu \mathrm{m}$ & (P08) \\
\hline$D_{g, v D M}(2 \mathrm{nd}$ mode $)$ & $3.0 \mu \mathrm{m}$ & (P08) \\
\hline$D_{g, \mathrm{BC}}$ & $0.2 \mu \mathrm{m}$ & $\mathrm{C} 04$ \\
\hline$D_{g, \mathrm{O}}^{g, \mathrm{BC}}$ & $0.2 \mu \mathrm{m}$ & C07, MJ95 \\
\hline$\sigma_{\mathrm{SO}_{4}}\left(1\right.$ st mode, $\left.9>z>H_{b l}\right)$ & 2 & M08 (INTEX-NA) \\
\hline$\sigma_{\mathrm{SO}_{4}}\left(2\right.$ nd mode, $\left.9>z>H_{b l}\right)$ & 1.86 & M08 (INTEX-NA) \\
\hline$\sigma_{\mathrm{SO}_{4}}\left(z<H_{b l}\right)$ & 1.80 & M08 (INTEX-NA) \\
\hline$\sigma_{\mathrm{SS}}$ & 2.12 & $\mathrm{M} 08, \mathrm{C} 06$ \\
\hline$\sigma_{\mathrm{solO}}$ & $\sigma_{\mathrm{SO}_{4}}$ & M08 \\
\hline$\sigma_{\mathrm{DM}}(1 \mathrm{st}$ mode $)$ & 1.9 & (P08) \\
\hline$\sigma_{\mathrm{DM}}(2 \mathrm{nd}$ mode $)$ & 1.6 & (P08) \\
\hline$\sigma_{\mathrm{BC}}$ & 1.6 & $\mathrm{C} 04$ \\
\hline$\sigma_{\mathrm{O}}$ & 2 & $\mathrm{C} 07$ \\
\hline$\rho_{\mathrm{SO}_{4}}$ & $1740 \mathrm{~kg} \mathrm{~m}^{-3}$ & Mi06 \\
\hline$\rho_{\mathrm{SS}}$ & $2170 \mathrm{~kg} \mathrm{~m}^{-3}$ & Mi06 \\
\hline$\rho_{\mathrm{solO}}$ & $1360 \mathrm{~kg} \mathrm{~m}^{-3}$ & Mi06 \\
\hline$\rho_{\mathrm{DM}}$ & $2300 \mathrm{~kg} \mathrm{~m}^{-3}$ & (P08) \\
\hline$\rho_{\mathrm{BC}}$ & $1860 \mathrm{~kg} \mathrm{~m}^{-3}$ & $\mathrm{C} 04$ \\
\hline$\rho_{\mathrm{O}}$ & $1500 \mathrm{~kg} \mathrm{~m}^{-3}$ & $\mathrm{C} 07$ \\
\hline
\end{tabular}

Table 2. Parameters of log-normal size distributions of aerosol for clean maritime conditions with meanings described in Table 1 . Only parameters that differ from continental conditions are listed.

\begin{tabular}{|c|c|c|}
\hline Symbol & Value & Origin \\
\hline$n_{1, \mathrm{SO}_{4}}: n_{2, \mathrm{SO}_{4}}\left(12>z>H_{b l}\right)$ & $170 \exp \left[\left(z-H_{b l}\right) / 2.4\right]: 150 \exp \left[-\left(z-H_{b l}\right) / 2.0\right]$ & M08 (INTEX-B) \\
\hline$n_{1, \mathrm{SO}_{4}}: n_{2, \mathrm{SO}_{4}}\left(z<H_{b l}\right)$ & $170: 150$ & M08 (INTEX-B) \\
\hline$n_{1, \mathrm{solO}}: n_{2, \mathrm{solO}}$ & $n_{1, \mathrm{SO}_{4}}: n_{2, \mathrm{SO}_{4}}$ & M08 \\
\hline$D_{g, \mathrm{SO}_{4}}\left(1\right.$ st mode, $\left.12>z>H_{b l}\right)$ & $0.04 \exp \left[-\left(z-H_{b l}\right) / 7.2\right] \mu \mathrm{m}$ & M08 (INTEX-B) \\
\hline$D_{g, \mathrm{SO}_{4}}\left(2\right.$ nd mode, $\left.12>z>H_{b l}\right)$ & $0.1 \mu \mathrm{m}$ & M08 (INTEX-B) \\
\hline$D_{g, \mathrm{SO}_{4}}\left(1\right.$ st mode, $\left.z<H_{b l}\right)$ & $0.033 \mu \mathrm{m}$ & M08 (INTEX-B) \\
\hline$D_{g, \mathrm{SO}_{4}}\left(2\right.$ nd mode, $\left.z<H_{b l}\right)$ & $0.15 \mu \mathrm{m}$ & M08 (INTEX-B) \\
\hline$D_{g, \mathrm{solO}}$ & $D_{g, \mathrm{SO}_{4}}$ & M08 \\
\hline$\sigma_{\mathrm{SO}_{4}}\left(\right.$ both modes, $\left.12>z>H_{b l}\right)$ & $2^{3,004}$ & M08 (INTEX-B) \\
\hline$\sigma_{\mathrm{SO}_{4}}\left(1\right.$ st mode, $\left.z<H_{b l}\right)$ & 1.48 & M08 (INTEX-B) \\
\hline$\sigma_{\mathrm{SO}_{4}}\left(2\right.$ nd mode, $\left.z<H_{b l}\right)$ & 1.51 & M08 (INTEX-B) \\
\hline$\sigma_{\mathrm{solO}}$ & $\sigma_{\mathrm{SO}_{4}}$ & M08 \\
\hline
\end{tabular}


Our most recent simulations not shown in the present paper have revealed only a very weak sensitivity of the control simulation described below (Sect. 4) to the choice of this soluble mass fraction of PBAPs within the range of 0.1 to 0.8 because insoluble organic aerosols are a small fraction of all aerosols. Yet over this range the critical supersaturation for CCN activation by a given insoluble organic core varies by a factor of 6 , and so the uncertainty must affect any perturbation simulations with very high loadings of PBAPs.) Such observations show that insoluble and soluble material are typically mixed together within the same aerosol particle. The mass of this soluble coating is simply diagnosed and is treated independently from the three soluble aerosol species. Over land, sulphate aerosol is assumed to be monomodal in the boundary layer and bimodal in the free troposphere, and approximately vice versa over the ocean.

Insoluble organic aerosols have a geometric mean diameter of $0.2 \mu \mathrm{m}$ (Clarke et al., 2004), consistent with field observations of size distributions of PBAPs by Matthias-Maser and Jaenicke (1995). They have a continuous spread of sizes extending towards the super-micron range.

\subsubsection{Prognostic variables}

Any given species of insoluble aerosol $(X=\mathrm{DM}, \mathrm{BC}$ or $\mathrm{O}$, for dust/metallic, black carbon or insoluble organic) may act as either an IN or a CCN (due to their soluble coatings) or both. Prognostic variables constraining the size distributions of its components that are in air ("interstitial") and immersed in cloud liquid are: (1) the "ideal" mass mixing ratio of insoluble aerosol particles $\left(Q_{X}\right)$ that would hypothetically exist without activation either as cloud droplets or as ice crystals; (2) the number mixing ratio of interstitial IN lost by their activation as ice crystals $\left(n_{X, a}\right)$; (3) the number mixing ratio of interstitial IN lost by becoming immersed in cloud liquid without necessarily freezing $\left(n_{X, a, \mathrm{imm}}\right)$; and (4) the number mixing ratio of IN immersed $\left(n_{X, \text { imm }}\right)$ inside cloud-liquid, which accounts for other losses of cloud droplets. Surface area (ideal) of insoluble aerosol is diagnosed from prognostic variables, (1)-(4). Here, $n_{X, a, i m m}$ and $Q_{X}$ determine the cut-off size between interstitial and immersed components.

For soluble species, which may have only CCN activity, only two of the above prognostic variables, $Q_{X}$ and $n_{X, a, \mathrm{imm}}$, are used $\left(n_{X, a, \text { imm }}\right.$ is not needed for soluble organic aerosol, assumed to be internally mixed with sulphate). Again, both constrain the cut-off size of the aerosol size distribution.

Sources and sinks of the variables describing aerosol size distributions are represented as noted below. All aerosol material immersed (dissolved or otherwise) or embedded in hydrometeors is assumed to remain contained in them during freezing or melting, with none liberated. This is because aerosol compounds can only partition between the liquid and solid aerosol phase.

Additionally, for each of the 6 species, mass mixing ratios are predicted for the following components of aerosol:
(1) actually existing interstitially in the air; (2) contained in all cloud-particles, whether liquid (immersed) or ice (embedded); and (3) contained in all precipitation (liquid or ice). This requires 3 variables for each aerosol species to diagnose their mass mixing ratios in air $\left(Q_{X \text {,air }}\right)$, cloud $\left(Q_{X \text {,cld }}\right)$ and precipitation $\left(Q_{X, \text { prec }}\right)$. These 3 variables are only used when the feedback from cloud/precipitation onto the environmental aerosol fields is predicted.

The fall speed of aerosol mass in the interstitial component is neglected, and in the other immersed/embedded components is simply the mass-weighted fall speed of the cloud ( $\left.Q_{X, \text { cld }}\right)$ or precipitation $\left(Q_{X, \text { prec }}\right)$ particles. The fall speed of $n_{X, \text { imm }}$ is the number-weighted fall speed of cloud droplets. Cycling of an aerosol species through clouds provides additional sources and sinks for its mass mixing ratios, as noted below.

\subsubsection{Physical processes involving aerosols}

The supersaturation determines nucleation of all cloud particles in the model, coupling the aerosol and cloud components prognostically. Supersaturation is predicted in-cloud by the bulk microphysics parameterisation and diagnosed at cloud-base (Sect. 2.3). Representations of known nucleation processes provide sources of number concentration of cloud droplets and ice crystals (cloud ice). Conversely, cycling of aerosol species through clouds is treated. Impacts, from clouds and precipitation on the concentrations of environmental aerosol species, are predicted explicitly.

The model represents physical processes that modify aerosol fields on time-scales of less than about a day. A justification for omitting slower processes than this is that environmental aerosol fields are re-initialised once every model day to prescribed values throughout the domain, as required to represent large-scale advection of aerosols (Sect. 3.2). Long-term effects from these slow aerosol-related processes are already included in the prescribed profiles. For instance, dry deposition is omitted because it is a slow process for aerosol particles in the size range and altitudes most relevant to cloud formation, involving gravitational sedimentation of aerosol particles to the surface. Equally, dry aerosol microphysics outside clouds is not treated explicitly and in nature causes aerosol size distributions to evolve on time-scales of days to weeks. Geometric mean diameters, standard deviations and number concentrations of aerosol are prescribed in the model using log-normal size distributions. Below-cloud scavenging by precipitation is much less effective than incloud scavenging (Flossmann and Pruppacher, 1988), so only the latter is included in this model treatment. Also, no chemical reactions are represented (these are less relevant for the ice phase and thus for this study than for the liquid phase), so the treatment of clouds' impacts on aerosols is purely physical.

The sources and sinks of interstitial aerosol are: (1) evaporation or sublimation of any hydrometeors; (2) large-scale 
advection of aerosol into the domain, implicitly represented as noted above; and (3) nucleation of cloud liquid or cloudice (deposition, conventional contact-freezing). The sources and sinks of aerosol material contained in cloud-particles are activation of interstitial aerosol, accretion of cloud by precipitation, and evaporation or sublimation of cloud-particles. This provides sources and sinks for the aerosol immersed or embedded in precipitation.

There follows a description of how each set of processes is treated.

Heterogeneous nucleation of hydrometeors: cloud-liquid is activated by all aerosol species. At cloud-base, the cloud droplet number is governed by loadings/chemical composition of soluble aerosol material and by updraft speed, according to the scheme of Ming et al. (2006). Inside the cloud, well above cloud-base, there is in-cloud activation of droplets by soluble aerosol species if the predicted supersaturation is high enough to activate particles smaller than the "cut-off size" (see below) of the aerosol size distribution, according to Köhler theory. Insoluble aerosols are assumed to have soluble coatings (Sect. 2.2) and their nucleation of droplets by activation of these soluble coatings is represented with $\kappa$ Köhler theory (Petters and Kreidenweis, 2007) at cloud-base and in-cloud. For instance, the CCN activity of insoluble organic (e.g. biological) aerosols with soluble coatings, and of dust, provides a source of extra cloud droplets in the model.

Cloud-ice is nucleated heterogeneously by insoluble aerosol species with the empirical parameterization (Phillips et al., 2008). The IN activity of a species of insoluble aerosol is related by the empirical parameterisation to the total surface area of its components that are interstitial and immersed in cloud-liquid. These components are constrained by prognostic variables noted above (1-4). Discretisation of the immersed and interstitial components of the IN size distribution with a temporary grid of bins allows the empirical parameterisation to represent all known modes of heterogeneous ice nucleation (condensation-, immersion- and conventional/inside-out contact-freezing modes, in addition to vapour deposition) at all sub-zero temperatures and humidities. Depletion of IN by ice nucleation is treated by incrementing $n_{X, a}$ by the number of ice crystals nucleated every time-step. Any heterogeneous freezing depletes $n_{X \text {,imm, }}$ according to the fraction of the number of supercooled cloud droplets lost during the time-step.

The feedback from clouds onto aerosols may be included as follows. $Q_{X \text {,cld }}$ is unchanged by freezing. When clear

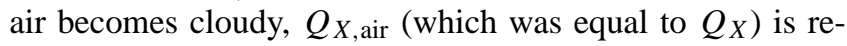
duced by the mass of aerosol activated. Finally, heterogeneous freezing of rain provides an extra source of graupel, as described by Phillips et al. (2008), but leaves $Q_{X \text {,prec }}$ unchanged. It does not affect the interstitial aerosol.

In summary, the known and empirically quantified mechanisms for heterogeneous activation of cloud-particles are represented in terms of their dependencies on predicted supersaturation, aerosol loading and chemical composition:
- in-cloud droplet nucleation (predicted supersaturation, $\kappa$-Köhler theory) and cloud-base droplet nucleation (peak supersaturation diagnosed by Ming et al. (2006), $\kappa$-Köhler theory);

- conventional and inside-out contact-freezing (empirical parameterisation);

- immersion-/condensation-freezing and deposition nucleation (empirical parameterisation);

Homogeneous nucleation of hydrometeors: homogeneous freezing of (interstitial) soluble aerosols is represented at cold levels above the mixed-phase region, as noted below (Sect. 2.3.3). This is done by discretizing the interstitial size distribution with a temporary grid of size-bins. Homogeneous freezing of cloud-liquid depletes $n_{X, \mathrm{imm}}$, according to the fraction of the number of cloud droplets frozen.

Evaporation and sublimation of hydrometeors: during

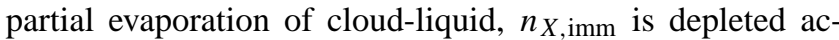
cording to the fraction of the number of supercooled cloud droplets lost. During partial evaporation of cloud or precipitation, $Q_{X \text {,cld }}$ or $Q_{X \text {, prec }}$ is reduced by the fraction by which the number or mass concentration of cloud-particles or precipitation respectively is reduced during each time-step. Then $Q_{X}$,air is incremented accordingly. When cloudy air becomes clear (total evaporation), $Q_{X}$, air is incremented by $Q_{X \text {,cld }}$ which is then set to zero, and $Q_{X}$ is set equal to this new value of $Q_{X \text {, air }}$.

Scavenging by precipitation: in-cloud precipitation scavenging of the immersed component of insoluble aerosol is represented by equating the fraction removed of $n_{X, \text { imm }}$ (and of $Q_{X \text {,cld }}$ ) with that of cloud droplet number accreted onto precipitation during every time-step, and similarly for the fraction removed of $n_{X, a, \mathrm{imm}}$ and $n_{X, a}$. Thus, the number of IN particles immersed in cloud-liquid is predicted, as for those existing interstitially. $Q_{X \text {,prec }}$ being incremented by the amount by which $Q_{X \text {,cld }}$ is reduced.

Transfers of aerosol material between its three components during other microphysical conversions are dealt with in a similar fashion.

\subsection{Cloud microphysics component}

The bulk microphysics parameterisation (Phillips et al., 2007) treats cloud processes with 5 classes of hydrometeor (cloud liquid, cloud ice, snow, graupel and rain), and includes sedimentation of cloud ice and cloud liquid. The scheme is double-moment insofar as the numbers of cloud droplets and ice crystals are predicted as well as their mass. Assumed shape-parameters of their size distributions allow their average size to be predicted, determining their mean fall-speeds and effective sizes for radiative properties of cloud. For ice crystals, a look-up table created from empirical formulae is used to infer the generalised effective size from the (numberweighted) mean size. Ice crystals are assumed to be columnar for the purposes of treating radiation and fall-speeds, a 
simplifying assumption. Only mass of precipitation species is predicted. No saturation adjustment or parameterisation of the Bergeron-Findeisen process is applied, since diffusional growth of cloud particles and precipitation is predicted explicitly with a linearised supersaturation scheme. More details are given by Phillips et al. (2007).

\subsubsection{Initiation of cloud-particles}

Known mechanisms for nucleation of cloud particles are represented by the double-moment bulk microphysics scheme, as described by Phillips et al. (2007) and with subsequent modifications noted here (Sects. 2.2, 2.3.3). Droplet activation occurs at cloud base, but also in the interior of the cloud at high supersaturations. Homogeneous freezing of supercooled cloud liquid occurs at the $-36^{\circ} \mathrm{C}$ level. Its representation allows for evaporation of an ascent-dependent fraction of cloud liquid near the $-36^{\circ} \mathrm{C}$ level, a process parameterized for the first time by Phillips et al. (2007). The H-M process (Hallett and Mossop, 1974) of ice particle multiplication is included.

\subsubsection{Initiation of precipitation}

Autoconversion of cloud liquid to rain depends on the mean droplet size implied by the predicted droplet number (and similarly for the autoconversion of cloud ice to snow). Conversion of snow to graupel depends on the riming rate. Sizedependence of collision efficiencies is assumed for the treatment of accretion of cloud liquid and cloud ice by precipitation.

\subsubsection{Recent modifications}

Recent improvements described here for the first time are: (1) the autoconversion scheme by Khairoutdinov and Kogan (2000) for the warm rain process is now applied; (2) accretion of cloud droplets by rain is done with the another scheme by Khairoutdinov and Kogan at cloud-liquid contents less than $1 \mathrm{~g} \mathrm{~m}^{-3}$ (the valid range of data used to construct their scheme), with the original treatment of accretion by Phillips et al. (2007) retained at higher cloud-liquid contents; (3) intercept-parameters of size distributions of precipitation species are now either functions of their mass mixing ratios (graupel, rain) or of temperature (snow), following Thompson et al. (2006); (4) an algorithm to detect a pre-existing cloud-base has been developed here for the first time, and determines for saturated grid-points whether cloud-base (diagnosed peak of supersaturation, unresolved) or in-cloud (predicted and resolved supersaturation) droplet nucleation is to be done; (5) homogeneous aerosol freezing now includes the effect from curvature and surface tension on the temperatureand size-dependent critical supersaturation, when applying the scheme of Koop et al. (2000); (6) internal mixing of soluble organic species with sulphate aerosol and of sulphate with insoluble species is represented by $\kappa$-Köhler theory (Petters and Kreidenweis, 2007), when treating droplet activation (e.g. by dust coated with soluble material) at cloud base and in-cloud. It has involved modifying the parameterisation by Ming et al. (2006) for activation of internal mixtures at cloud-base.

The above routine for cloud-base detection traces the streamline of the ascending flow (relative to the mean horizontal wind) downwards to the adjacent vertical level. There the "upstream" value of cloud droplet number is found. It will be negligible if there is a pre-existing cloud-base. This routine allows the the scheme of Ming et al. (2006) to be applied continuously where a cloud-base persists.

\subsection{Ice nucleation by biological and other insoluble or- ganic aerosols}

An empirical parameterisation of heterogeneous ice nucleation by Phillips et al. (2008) has been implemented in the CSRM. The empirical parameterisation predicts the numbers of ice crystals nucleated heterogeneously by each basic group of insoluble aerosols for any aerosol scenario in general. It is based on coincident field measurements of IN activity and aerosol loadings in the free troposphere on Mt Werner in Colorado (DeMott et al., 2003a). It includes dependencies on the predicted supersaturation and (surface area) mixing ratio of three groups of chemical species of IN aerosols $(X=D M$, $B C$, and $O$ )

The empirical parameterisation represents the known and empirically quantified modes of heterogeneous ice nucleation. It was recently validated by Eidhammer et al. (2009) in microphysical simulations of wave-clouds observed in the ICE-L field campaign. Dust rather than carbonaceous aerosols likely dominated the IN activity there. The clouds were confined to temperatures where heterogeneous ice nucleation is thought to prevail, without any H-M process or homogeneous freezing. The empirical parameterisation was found to predict the observed ice concentration with an error of less than half an order of magnitude. By contrast, other alternative existing schemes from the literature did not predict the correct order of magnitude.

Ice nucleation by PBAPs and other insoluble organic aerosols is treated by the empirical parameterisation. During its construction, insoluble organic IN were supposed to have nucleated about $6 \%$ of all heterogeneous ice crystals in air sampled at Mt. Werner, Colorado. The air likely originated from the background troposphere. There was significant uncertainty associated with this estimated fraction, owing to ambiguity in analysis of the composition of IN inside the heterogeneously nucleated ice crystals sampled from the atmosphere. Also, there was uncertainty in total cell concentrations assumed. With this empirical parameterisation implemented in a cloud model, the fractional contribution from insoluble organic aerosols, to the total predicted number of het- 


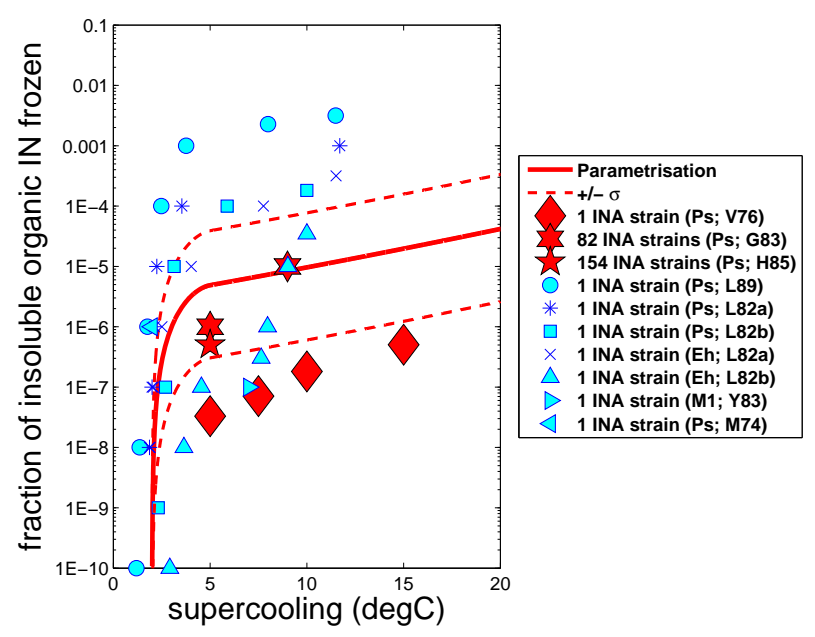

Fig. 1. Frozen fraction of insoluble organic particles predicted by the empirical parameterisation and inferred from laboratory studies of the immersion-freezing of bacteria. The observed freezing fractions for INA strains have been multiplied by 0.01 (Lindemann et al., 1982) to convert them to freezing fractions for all strains (INA and non-INA). Many INA strains of Pseudomonas syringae ("Ps") were analysed by Gross et al. (1983 ["G83"]) and Hirano et al. (1985 ["H85"]). The freezing of single INA strains of Ps (Maki et al., 1974 ["M74"]; Vali et al., 1976 ["V76"]; Lindow, 1982 ["L82a"]; Lindow et al., 1982 ["L82b"]; Lindow et al., 1989 ["L89”]), M1 (Levin and Yankofsky, 1983 [“LY83”]) and Erwinia Herbicola ("Eh';; L82a,b) are also shown. Except for the observations by Gross et al. (1983) Hirano et al. (1985) and Vali et al. (1976) (red symbols), the displayed data were not used in construction of the scheme. Error bars (red dashed lines) for the parameterisation include contributions from uncertainty in the aerosol size distribution and in the estimation of parameters during construction of the scheme, as explained by Phillips et al. (2008).

erogeneously nucleated ice crystals, varies with their loading as it must do in nature. It is not 6\% in general, but instead differs from this by a factor that depends on the total surface area of insoluble organic aerosols.

About half of the ice crystals nucleated by the insoluble organic aerosol group were estimated to originate from INA bacteria, and this estimate is uncertain. Cells expressing the INA phenotype represent only a small fraction (1\%; Lindemann et al., 1982) of all non-viable and viable airborne bacteria cells $\left(10-1000 \mathrm{~L}^{-1}\right)$ in the troposphere, which are estimated by Phillips et al. (2008) to have a likely average concentration of about $100 \mathrm{~L}^{-1}$. Observed fractions of the INA bacteria that freeze (e.g. Vali et al., 1976; Gross et al., 1983; Hirano et al., 1985) during supercooling partly constrain the treatment of insoluble organic IN (e.g. INA bacteria) for the empirical parameterisation, as described by Phillips et al. (2008).

To test the performance of the scheme off-line, its prediction is compared with available laboratory observations of INA bacteria. Typical observed values of mean aerosol size and spectral width have been applied (Phillips et al., 2008) to infer a predicted freezing fraction. As explained by Phillips et al. (2008), the comparison applies to a wide range of aerosol scenarios because the predicted freezing fraction does not depend on any assumed aerosol concentration.

Figure 1 shows that the prediction for insoluble organic IN from the empirical parameterisation (Phillips et al., 2008) agrees with independent (plotted in blue) laboratory observations of INA bacteria over most of experimental temperature range. It is mostly within the range of their freezing fractions, which vary over several orders of magnitude at any given temperature. Over the entire experimental temperature range, the prediction agrees with the combined set of all experimental data (blue and red points denote data that are independent and used in construction of the scheme, respectively), being not far from their geometric mean.

Observed freezing fractions for single INA strains shown in Fig. 1 vary by many orders of magnitude at any given supercooling. That is expected from the lognormal distribution of nucleating ability among strains seen by Hirano et al. (1985). Finally, there is a tendency towards the colder experimental temperatures for the independent data (blue points) in Fig. 1 to display higher freezing fractions than predicted. This tendency is explicable in terms of single bacterial strains that were highly effective at nucleating ice having been preferentially selected for those laboratory studies. The extensive data from Hirano et al. (1985) and Gross et al. (1983), (red points), was assumed to be representative of INA bacteria in nature and agrees well, by design, with the empirical parameterisation.

\section{Description of cases and experimental set-up}

The ARM-SGP-1997 period in Oklahoma was selected for the present study of the role of biological aerosols for three reasons. Firstly, ARM-SGP-1997 includes observations of large-scale advection of heat and moisture needed to force the CSRM over long periods. Secondly, the aerosol conditions and convection there are continental. Biological aerosol particles typically have land sources. Thirdly, it occurs during summertime and Oklahoma is quite near the Mid-West USA. $P$. syringae has been observed to be rife as a plant disease in fields of wheat and barley in the Mid-West during the growing season (Caristi et al., 1991). Cells of $P$. syringae can become airborne (Lindemann et al., 1982), being detached from plant surfaces and aerosolised. Consequently, scenarios of copious airborne INA bacteria would seem plausible for the vicinity of Oklahoma in early summer near sources on the ground.

A slight disadvantage of ARM-SGP-1997 is that no aircraft observations of cloud properties were made during it. This limits the acuity of validation of cloud-particle concentrations (Sect. 4). However, other statistics that depend on cloud cover and properties (e.g. radiative fluxes, cloud frac- 
tion, precipitation, temperature fields) were measured during ARM-SGP-1997, enabling a direct comparison with the simulation.

\subsection{Observed characteristics of cases}

The ARM-SGP-1997 period (Oklahoma, 19 June-17 July 1997) consists of several episodes of vigorous deep convection. This period includes three sub-cases $(\mathrm{A}-\mathrm{C})$ simulated individually by Phillips and Donner (2006), as well as an extra couple of weeks of convection. The ARM observations for it are described in detail by Xu et al. (2002). Vigorous deep convection was seen, as evinced by intense precipitation. Associated stratiform cloud was also produced. The storms were caused by intense destabilisation by large-scale advective cooling in the mid-troposphere. The free troposphere was quite dry, with a relative humidity of only about $30-60 \%$ with respect to water and ice at 5 and $10 \mathrm{~km}$ above mean sea level (MSL), respectively. There was moderate shear in most of the free troposphere.

\subsection{Design of experiments}

The experimental design of all simulations of cloud ensembles follows Phillips and Donner (2006) and Phillips et al. (2007). In experiments performed here, the aerosol-cloud model (Sect. 2), a CSRM, is integrated with horizontal and vertical resolutions of 2 and $0.5 \mathrm{~km}$, respectively. A time step of $10 \mathrm{~s}$ is used and the vertical grid has 40 levels. The domain is 2-D and has a width of about $170 \mathrm{~km}$ (85 grid points). Many types of cloud, and entire mesoscale cloud-systems, can be resolved simultaneously in this domain. All lateral boundary conditions are periodic for all prognostic variables.

Biases of the amounts of microphysical species (about 10$20 \%$ ) and domain-wide radiative fluxes (less than $20 \mathrm{~W} \mathrm{~m}^{-2}$ ) were found by Phillips and Donner (2006) to arise from exclusion of the third dimension in an earlier version of our CSRM. However, these biases were found by Phillips and Donner (2006) to be systematic and limited, due to updrafts being consistently too slow in 2-D. The numerical experiments (Sect. 5) are relative ones, in the present study. They are unaffected by any systematic errors as noted below (Sect. 4). Hence, 2-D simulations suffice for sensitivity studies here, just as they did for similar studies with an earlier version of our double-moment cloud model by Phillips et al. (2007).

The "control" run for the sensitivity study here (Sect. 5) is a simulation of ARM-SGP-1997 over Oklahoma during summer. It is validated in the next section (Sect. 4). For this control run, the CSRM is initialised with observed profiles of temperature and humidity from ARM (Zhang et al., 2001). As no coincident aerosol observations in most of the troposphere were available, the CSRM was initialised with aerosol mixing ratios predicted for the same month as each case by the GFDL General Circulation Model (GCM),
(GFDL GAMDT, 2004; Horowitz, 2006), for all species except sulphate.

Generally, sulphate aerosols often largely determine the overall CCN concentration and $\mathrm{CCN}$ can be more important than IN for the glaciation of convection that is deep (Phillips et al., 2007). Consequently, the concentration of ammonium sulphate aerosol in the control run was initialised using aircraft observations from INTEX-NA (eastern North America, July 2004), (McNaughton, 2008). Yet INTEX-NA occurred in states other than Oklahoma. Hence, the sulphate aerosol loading from INTEX-NA was halved at all levels so as to match it at the lowest model level with that observed $\left(2 \mu \mathrm{g} \mathrm{m}^{-3}\right)$ in July by the Inter-agency Monitoring PRogram for Visual Environments (IMPROVE) at a nearby station, Wichita Mountains, Oklahoma, close to the simulated location of the ARM-SGP site. When combined with parameter values for aerosol size distributions noted above (Sect. 2.2), the resulting profile of sulphate aerosol reproduced accurately the real concentrations of aerosol particles of all species, both at sizes $>0.01 \mu \mathrm{m}$ and $>0.1 \mu \mathrm{m}$, measured near the ground in Oklahoma during ARM-SGP-1997 (Sheridan et al., 2001).

Convection is maintained by applying tendencies to represent large-scale advection of humidity and temperature. These were derived from ARM-SGP observations by Zhang et al. (2001). Perturbations are imposed onto the initial field of vapour mixing ratio so as to initiate convection, following Phillips and Donner (2006). Properties of the Earth's surface (temperature, albedo, emissivity) are prescribed from observations. Surface fluxes of heat and moisture are predicted with standard schemes from the WRF infrastructure.

The feedback from clouds onto the aerosol fields is represented in the control run. Environmental aerosol species are replenished by evaporation or sublimation, and depleted by nucleation. Aerosol profiles are restored to their initial values once every $24 \mathrm{~h}$, following Salzmann et al. (2007), implicitly representing the large-scale advection of aerosol mass into the domain and the action of slow aerosol-related processes.

There is the option in our model for the feedback from clouds onto the environmental aerosol fields to be switched off (the "no-feedback case"). This involves prescribing the initial aerosol profiles everywhere outside clouds throughout the entire duration of simulations. In all other simulations of the present study, including the control run, this feedback is included, however.

\section{Results from validation of control simulation for con- tinental convection over Oklahoma}

The focus of the present paper is to analyse effects from biological aerosols using sensitivity tests with a model. These numerical experiments are relative ones and reveal differences in various quantities (e.g. in the order of magnitude of cloud-particle concentrations) between the control and per- 
turbation simulations. Such a difference for a given quantity is not affected by any systematic error in predicting it. Absolute near-perfect accuracy of the control run is not needed for our numerical experiments.

Nevertheless, the control simulation of ARM-SGP-1997 over Oklahoma by the aerosol-cloud model (Sects. 2, 3.2) is compared here with aircraft, satellite and ground-based observations. The aim is to show that the model does not diverge strongly from available observations. They are either from ARM-SGP-1997 itself or, if not available, from elsewhere in the continental USA. Many ensembles consisting of continental convective and stratiform clouds are included in the simulation. It lasts almost a month.

Vertical profiles displayed throughout the present study are averaged over the entire duration of the simulation (excluding the initial 2 days of "spin-up" for unconditionally averaged profiles). Averaging of cloud properties is done conditionally over certain types of region (e.g. visible cloud), except for cloud-liquid water path that is averaged unconditionally across the whole domain. Throughout the present paper, "upper-level cirrus" is defined as cloud higher than $10 \mathrm{~km}$ above the ground (well above the mixed-phase region) with appreciable ice concentrations $>1 \mathrm{~L}^{-1}$. Cloud is defined as "visible" or "highly visible" when the normal (vertical) optical depth of its grid-box $(0.5 \mathrm{~km}$ deep) is predicted to exceed assumed thresholds of 0.2 or 3 , respectively, following Phillips et al. (2007).

To demonstrate that accuracy is robust for contrasting aerosol conditions, Appendix A shows validation of simulations of two extra cases of tropical maritime convection with the same version of the model (Sect. 2). They are not used for any biological sensitivity tests in the present paper.

\subsection{Cloud properties}

The average fraction of the domain covered by visible cloud in the control run (ARM-SGP-1997) is predicted to be about $5 \%$ over most of the depth of the mixed-phase region (about 4-9 km altitude above the ground). The predicted total concentration of all cloud-ice particles, averaged throughout the entire domain, is of the order of $10-100 \mathrm{~cm}^{-3}$ and $0.1-$ $10 \mathrm{~cm}^{-3}$ above and within the mixed-phase region, respectively. Such high concentrations aloft are due to homogeneous freezing of $\mathrm{CCN}$ or their cloud droplets above the mixed-phase region. The homogeneously frozen ice then descends through the mesoscale domain, as found for other instances of vigorous deep convection (e.g. Heymsfield et al., 2005; Phillips et al., 2007).

No aircraft observations of cloud properties were made during the ARM-SGP-1997 period of summer 1997 in Oklahoma. Hence, the control simulation is compared with aircraft data from the following two groups of other field experiments in North America, one with (plotted in blue) and one without (plotted in red) upper-level cirrus present. Firstly, there are four datasets of aircraft observations of summer- time deep cumulus (e.g. cumulus congestus) clouds without anvils, with cloud-tops and -bases located in and below the mixed-phase region, respectively, in New Mexico (Blyth and Latham, 1993; Blyth et al., 1997; see also Phillips et al., 2001), Montana in the High Plains Cooperative Program (HIPLEX, 1979-1980) and in the Florida Area Cumulus Experiment (FACE, 1978), (Harris-Hobbs and Cooper, 1987). Secondly, observations of convection with cirrus during the Bow-Echo and MCV Experiment (BAMEX) (eastern USA, summer 2003) and in the ARM-Southern Great Plains (SGP2000) field experiment (Oklahoma, spring 2000; Heymsfield et al., 2002a) have also been used.

Concentrations of ice particles $(>70 \mu \mathrm{m})$ were measured with the 2D-Cloud (2D-C) probe. Cloud droplet concentrations were measured with the Forward Scattering Spectrometer Probe (FSSP). Validation of the model is performed by predicting the component of number concentrations of particles for sizes detected by these probes. There is a direct comparison between the model and observations.

Figure 2a shows the predicted number concentration of ice particles $(>70 \mu \mathrm{m})$ averaged over visible, mixed-phase convective updrafts $>1 \mathrm{~m} \mathrm{~s}^{-1}$ without much upper-level cirrus (defined above, plotted in red). It increases with height from about 1 to $30 \mathrm{~L}^{-1}$ over the depth of the H-M generation region $\left(-3\right.$ to $\left.-8^{\circ} \mathrm{C}\right)$, due to the $\mathrm{H}-\mathrm{M}$ process of splinter production. The observed trend of logarithmically increasing mean concentration with height over the H-M region, for the New Mexican cumulus cloud sampled at multiple levels in 1993 (Blyth et al., 1997), is reproduced well. The error of the prediction near $-10^{\circ} \mathrm{C}$ is only about $10 \%$ (see uppermost red triangle).

The predicted mean concentration of ice is significantly larger (by about $700 \%$ or 1-2 standard deviations) than corresponding observations from convective clouds over Montana and Florida. There, instability, cloud dynamics and loadings of aerosol species in the real troposphere must have been different relative to Oklahoma. Both states are far from the ARM-SGP site. Also, the H-M process is multiplicative and inherently difficult to model. It generated most of the ice particles in the convective updrafts observed (Harris-Hobbs and Cooper, 1987) and simulated here. The predicted mean 2D-C concentration is lower than almost all of the twenty instantaneous maximum values for convective clouds observed in 1987 over New Mexico (Blyth and Latham, 1993), as required for it to approximate their mean values (data not available). These observed maxima tend to increase with height. (However, a similar trend in the mean ice concentration in the real clouds is not to be expected because there may have been an increase with height of the variability in ice concentration, as we have seen for cloud-decks sampled in ARMSGP-2000.) The predicted mean concentration of ice does not increase markedly with height in the mixed-phase region above the H-M region, as expected from the dominance of the H-M process seen by Harris-Hobbs and Cooper in such convective clouds. 
(a)

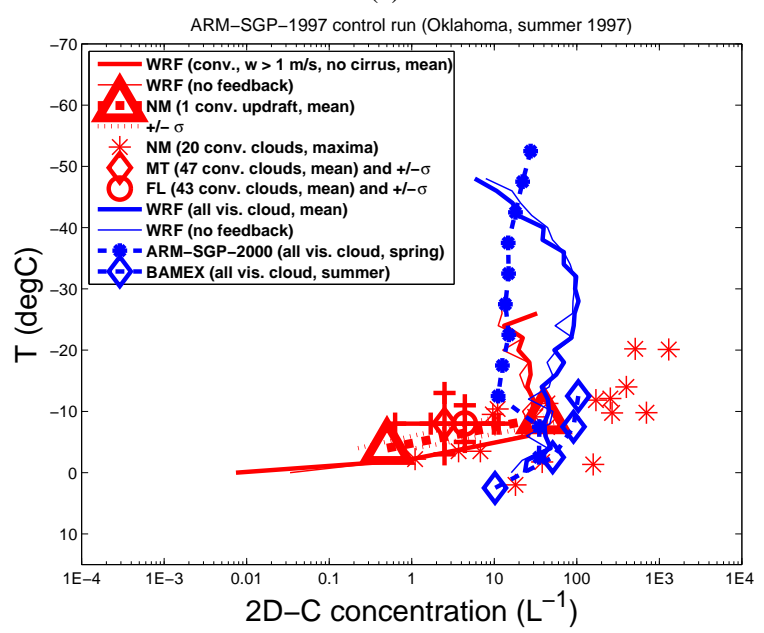

(b)

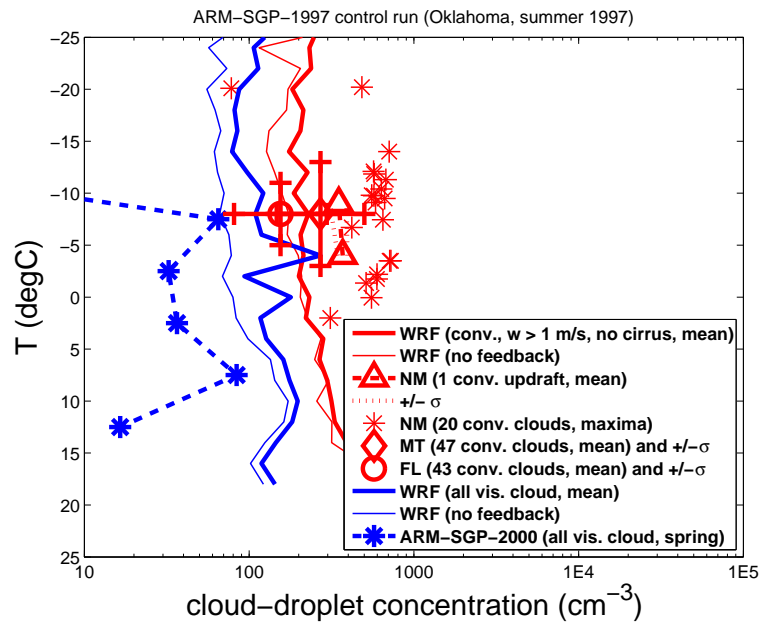

Fig. 2. Number concentrations of (a) ice particles ( $>70 \mu \mathrm{m})$; and (b) cloud droplets, predicted in the ARM control run ("WRF") and observed by aircraft with the 2D-C probe and FSSP for visibly cloudy, convective updrafts (normal optical depth of $0.5-\mathrm{km}$ layer $>0.2$, vertical velocities $>1 \mathrm{~m} / \mathrm{s}$ ) without upper-level cirrus above them (plotted in red). Cirrus in the simulation is defined by ice crystal concentrations exceeding $1 \mathrm{~L}^{-1}$ anywhere between 10 and $20 \mathrm{~km}$ above the ground in the same grid-column as any grid-point belonging to a visible cloudy updraft. The predicted profile is a conditional average for such updrafts over the entire duration and domain of the simulation. The aircraft data is from multiple traverses through a New Mexican ("NM") cumulus cloud (Blyth et al., 1997). Observations are displayed of maximum values of concentrations from various New Mexican convective clouds ("NM"; Blyth and Latham, 1993) and mean values from clouds sampled in HIPLEX and FACE over Montana ("MT") and Florida ("FL"), (Harris-Hobbs and Cooper, 1987). The prediction without the feedback from clouds onto the aerosol fields is displayed too (thin continuous lines). Also shown are the corresponding concentrations for all visible cloud (plotted in blue), irrespective of vertical velocity and of whether cirrus is present aloft, using aircraft data from ARM-SGP-2000 (spring 2000) and BAMEX (summer 2003) field campaigns over the eastern USA.
Also shown in Fig. 2a is the 2D-C concentration of ice particles $(>70 \mu \mathrm{m})$ averaged conditionally over all visible cloud, regardless of whether upper-level cirrus is present (plotted in blue). This prediction is intermediate between observed values from BAMEX and ARM-SGP-2000. In the lower half of the mixed-phase region, the predicted ice concentration has an error of only about $10 \%$ compared to BAMEX (its P3 aircraft have a ceiling of only about $8 \mathrm{~km}$ above the ground). Convection seen in BAMEX was vigorous. It occurred in the same season as that simulated (summer), and is more similar to the convection seen in ARM-SGP-1997, the campaign simulated, than is ARMSGP-2000. The predicted ice concentration is up to half an order of magnitude higher throughout most of the mixedphase region than in ARM-SGP-2000. This would be consistent with real updrafts in ARM-SGP-2000 being slower and forcing a lower supersaturation, which then activates and maintains fewer cloud droplets, especially supercooled ones. Fewer then freeze aloft in ARM-SGP-2000 than in the control run.

Figure $2 b$ shows the predicted mean concentration of cloud droplets. It is about $200-400 \mathrm{~cm}^{-3}$ in convective updrafts in and below the mixed-phase region without cirrus aloft. The predicted mean value differs by only about $10 \%$ (less than one standard deviation of the observations) from that seen in the single deep cumulus updraft in New Mexico in 1993. It is less than almost all of the observed maxima of instantaneous values from the 20 clouds sampled in 1987 over New Mexico, as required for it to approximate their mean values (data not available). Moreover, the predicted order of magnitude is consistent with detailed simulations with spectral microphysics models of individual cells of continental deep convection over New Mexico and Texas (e.g. Phillips et al., 2001, 2002; Khain et al., 2004; Khain and Pokrovsky, 2004). It is intermediate between observed mean values for Florida and Montana. Such variability in observed concentrations of cloud droplets partly arises from that of normalised CCN concentrations across the USA (e.g. Hobbs et al., 1985), (see also Pruppacher and Klett, 1997).

The no-feedback case without the feedback from clouds onto the aerosol fields (Fig. 2) produces slightly lower concentrations of cloud droplets aloft than in the control run. This feedback modifies cloud-particle numbers more at higher, colder levels than in the lower troposphere in the control run. Aerosols are scarce at upper levels and replenished by outflow from deep convection, which upwells them. Aerosols may go through successive cycles of activation, incloud transport, re-generation in cloud-free air by evaporation of cloud, and entrainment into clouds again, during a single model day, as in nature.

Figure 3 shows the evolution of the cloud-liquid water path, expressed in terms of the equivalent depth of liquid water at the surface. It is compared with observational data provided by the ARM Cloud Properties Working Group (Xu et al., 2002), derived from satellite measurements with the 


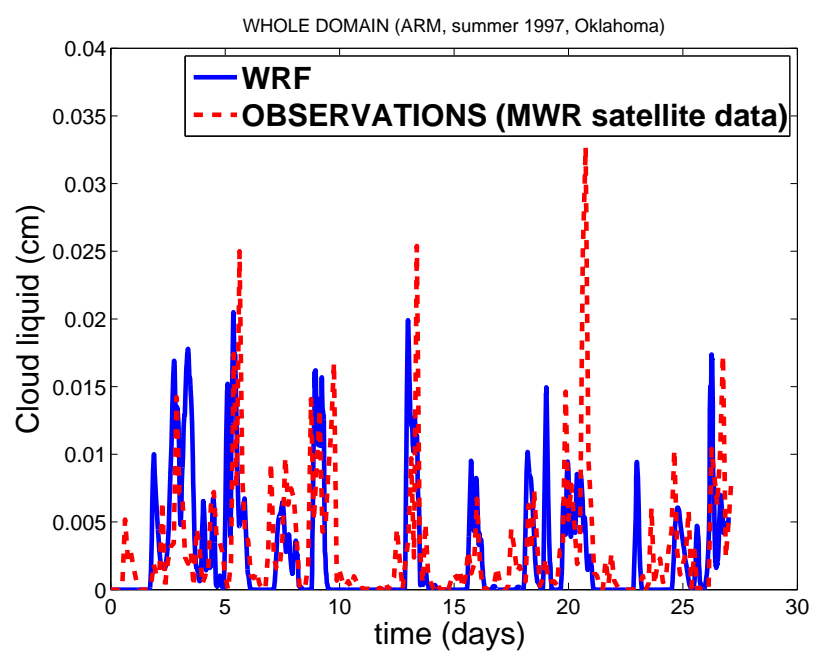

Fig. 3. Cloud-liquid water path predicted in the ARM control run ("WRF") and inferred from MWR satellite data. The first couple of days of the simulation are omitted for spin-up of the model.

microwave radiometer (MWR), (Liljegren, 1994). The prediction averaged over the simulated period displayed has a relative error of $15 \%$, being slightly lower than the observation. This relative error is less than that of the uncertainty of inferring cloud-liquid water path from the satellite data (absolute measurement error of $0.003 \mathrm{~cm}$ ), (Xu et al., 2002). On two days (19 and 20) the simulation over- and underestimates a couple of intense peaks. For all other days, peak predicted values of the instantaneous cloud-liquid water path all have relative errors of less than about $30 \%$. Such errors are comparable with the measurement uncertainty noted above.

In summary, the difference between the predicted number concentrations of cloud-ice in deep convection, and observed mean values from different field experiments done elsewhere over the continental USA is less than, or comparable to, differences between these various observed values. The same is true for cloud-liquid.

\subsection{Thermodynamical, radiative and precipitation statistics}

The mean errors of temperature and vapour mixing ratio for the month-long ARM-SGP-1997 period are displayed in Fig. 4. Their absolute magnitudes are less than about $1 \mathrm{~K}$ and $1 \mathrm{~g} / \mathrm{kg}$ at all levels. RMS errors of temperature and vapour mixing ratio (not shown) are similar. The mean errors here are comparable to or less than those from other CSRM studies of convection at the Oklahoma ARM site displayed by Ghan et al. (2000) and Xu et al. (2002).

Table 3 shows the predicted and observed radiative fluxes, averaged over the whole mesoscale domain and simulated period. Observed radiative fluxes were obtained from the ARM web-site (see also Xie et al., 2002), being derived from
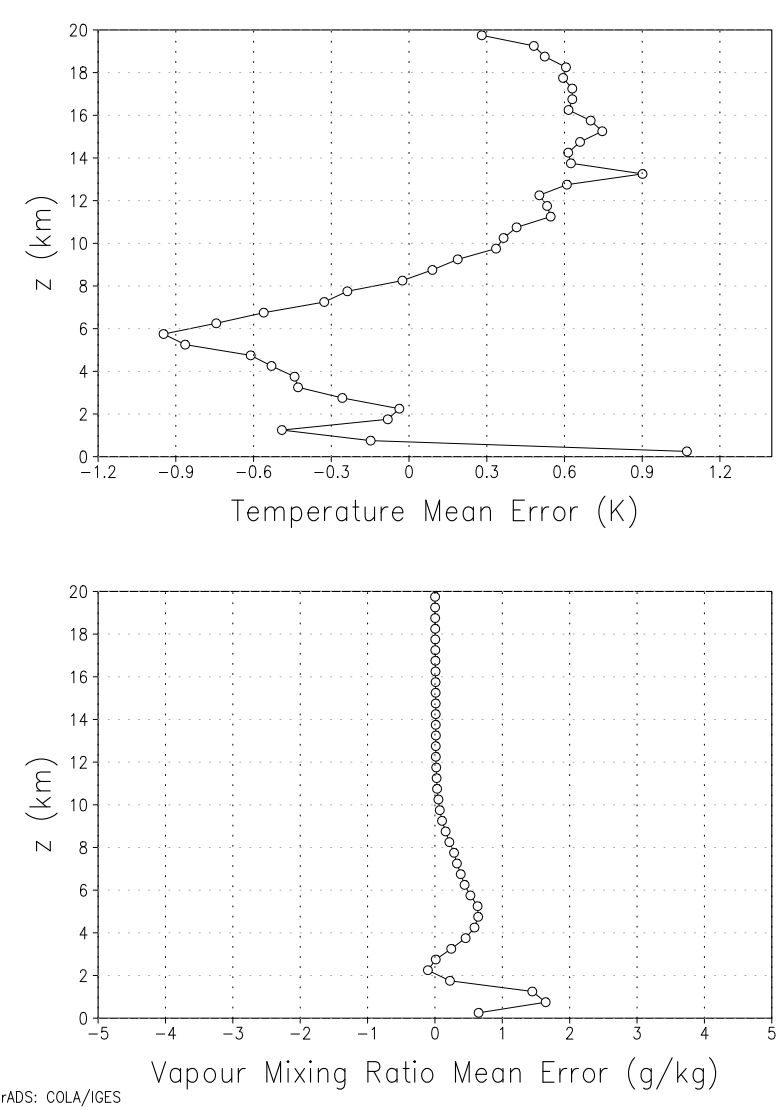

Fig. 4. Mean errors of temperature and vapour mixing ratio for the control run of the month-long ARM-SGP-1997 period. These quantities are unconditionally averaged over the entire domain and duration of the simulation, except that the first 2 days are omitted for spin-up of the model.

satellite data. At the top of the atmosphere (TOA), relative errors in the predicted upward components of radiative fluxes are less than $14 \%$. At the surface, relative errors in the predicted downward components of radiative fluxes for ARM are comparable with those of the measurement uncertainty (about 25 and $10 \%$ in the short- and long-wave respectively; Appendix A). Such relative errors are less than, or comparable to, those from previous CSRM studies of Oklahoma convection at the ARM-SGP site (Ghan et al., 2000). Radiative fluxes, especially in the shortwave, are sensitive to number concentrations of cloud-particles, which are aerosol-sensitive and determine their mean size, fall-speeds, cloud radiative properties and cloud extent. Hence, the evident accuracy of radiative fluxes is consistent with predicted concentrations of ice and droplets also being accurate (Fig. 2).

Figure 6 shows the total amount of accumulated precipitation at the ground. The error in the prediction for the whole month simulated is only about $7 \%$. All major episodes of intense precipitation are reproduced. Predicted and observed peak rates of surface precipitation (not shown) differ by less 
Table 3. Longwave and shortwave fluxes at the top of the atmosphere (TOA) and ground (SFC) for upward and downward components respectively. Control simulations with our aerosol-cloud model, and a run without inclusion of the feedback from clouds onto environmental aerosol fields (no-feedback case), are denoted by WRF and WRF', respectively. Percentage errors are given in parenthesis. Predicted fluxes displayed are averaged over the entire domain and duration of the simulation, except that the first 2 days are omitted for spin-up of the model.

\begin{tabular}{llllll|}
\hline \multirow{2}{*}{ Case } & $\begin{array}{l}\text { Simulation/ } \\
\text { observations }\end{array}$ & \multicolumn{2}{l}{ SHORTWAVE FLUX $\left(\mathrm{W} \mathrm{m}^{-2}\right)$} & \multicolumn{2}{l}{ LONGWAVE FLUX $\left(\mathrm{W} \mathrm{m}^{-2}\right)$} \\
\cline { 3 - 6 } & & $\begin{array}{l}\text { TOA } \\
\text { upwards }\end{array}$ & $\begin{array}{l}\text { SFC } \\
\text { downwards }\end{array}$ & $\begin{array}{l}\text { TOA } \\
\text { upwards }\end{array}$ & $\begin{array}{l}\text { SFC } \\
\text { downwards }\end{array}$ \\
\hline \multirow{2}{*}{ ARM } & WRF (control) & $127.6(14 \%)$ & $320.1(13 \%)$ & $250.6(-4 \%)$ & $346.4(-12 \%)$ \\
& WRF' & $131.3(17 \%)$ & $315.2(11 \%)$ & $249.3(-4 \%)$ & $347.5(-12 \%)$ \\
& Observed & 112.0 & 283.3 & 261.2 & 393.9 \\
\hline
\end{tabular}
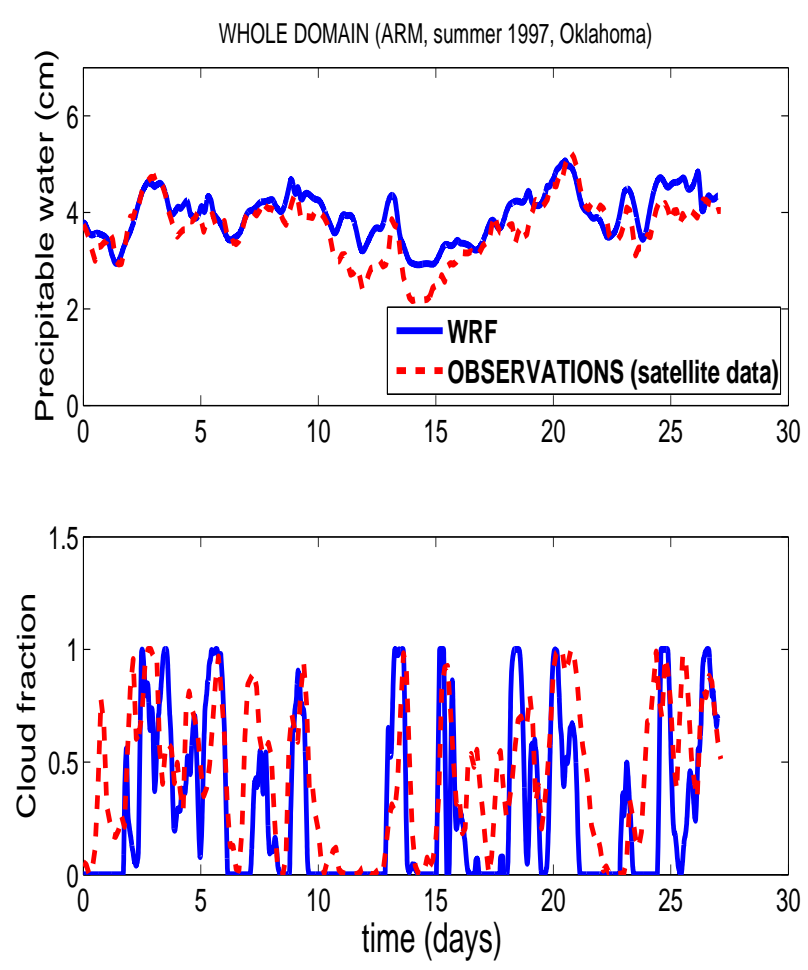

Fig. 5. Precipitable water path (upper panel) and column cloud fraction (lower panel) predicted in the ARM-SGP-1997 control run ("WRF"), in comparison with values inferred from MWR and GOES-7 satellite data, respectively. The first couple of days of the simulation are omitted for spin-up of the model.

than a factor of about 2 for most episodes of intense precipitation, as with simulations of this ARM-SGP-1997 period by Khairoutdinov et al. (2003) and Xu et al. (2002).

Figure 5 shows the precipitable water path. It is defined as the column amount of water vapour expressed in terms of the equivalent depth of liquid water of the same mass at the surface. It is compared with ARM observations (Xu et al., 2002) inferred from radiosonde and MWR satellite data (Liljegren, 1994). When averaged over the entire simulated

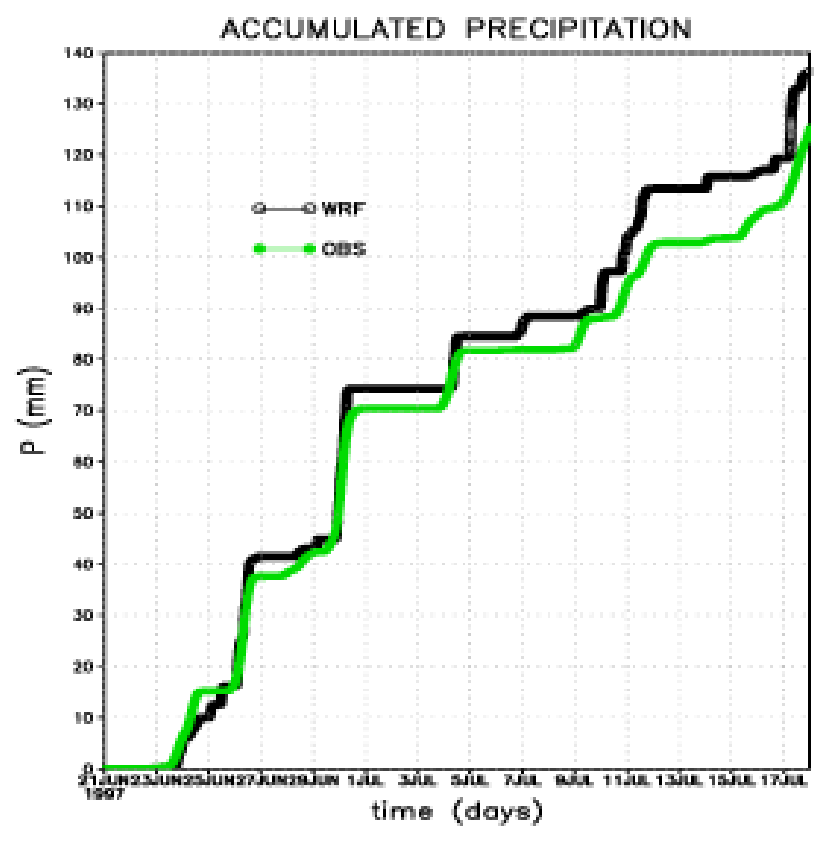

Fig. 6. Observed and predicted ("WRF") domain-wide accumulated surface precipitation during ARM-SGP-1997. The first couple of days are omitted for spin-up of the model.

period displayed, the prediction is about $8 \%$ higher than observed. Instantaneous values of precipitable water path always have relative errors of less than about $15 \%$.

Also shown in Fig. 5 is the "column cloud fraction". In the simulation, it is defined as the fraction of all grid-columns with a combined cloud-liquid and -ice water path exceeding $10 \mathrm{~kg} \mathrm{~m}^{-2}$ (Xu et al., 2002). It is compared with the column cloud fraction inferred by the ARM Cloud Properties Working Group from observations with the GOES-7 satellite, using the method of Minnis et al. (1995). The prediction (0.3) is lower than observed (0.4) with a relative error of about $30 \%$, when averaged over the whole simulated period displayed. Other (10) CSRMs validated by Xu et al. (2002, Table 9 therein) had relative errors of at least about $50 \%$ for each 
(a)

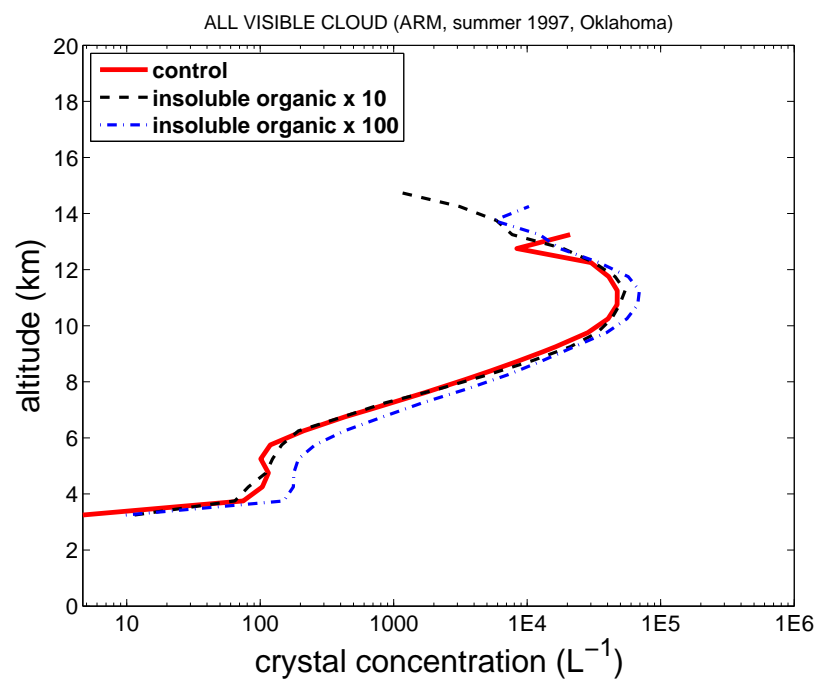

(b)

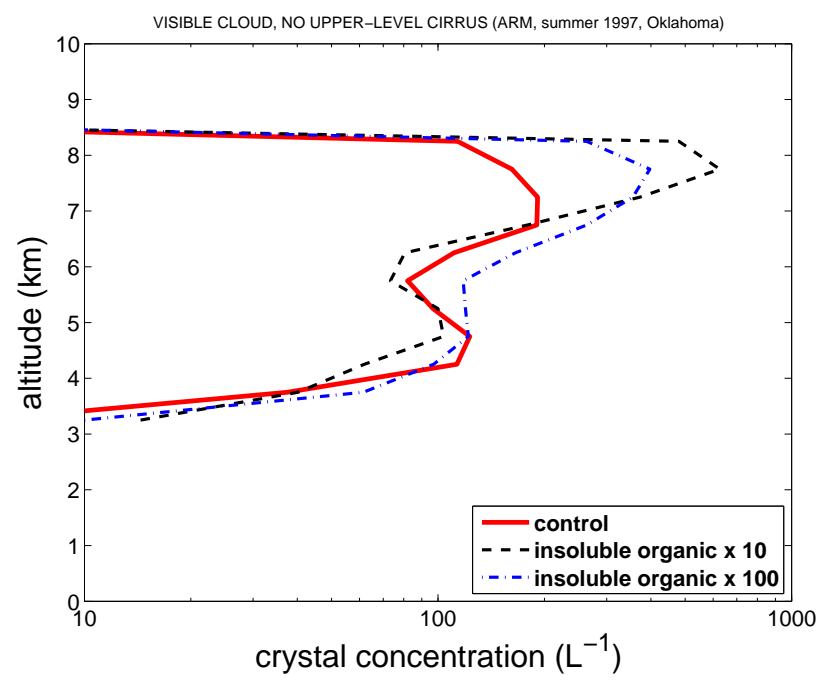

Fig. 7. Crystal number concentration versus height above the ground for the control and for high and ultra-high bio-aerosol cases. It is conditionally averaged for the entire duration of the simulation over regions of visible cloud (normal optical depth $>0.2$ over a $500 \mathrm{~m}$ layer) (a) throughout the whole domain and (b) without upper-level cirrus in the same grid-column (defined in the text).

sub-case (A-C) during ARM-SGP-1997. Generally, the typical spatial resolution of CSRMs does not resolve the smaller shallow clouds in the lower troposphere, causing the cloud fraction to be under-estimated. On the initial day or so, the present model displays a classic delay of the onset of vigorous deep convection, typical of CSRMs generally, followed by an over-shoot of intensity (e.g. Xu et al., 2002). For the rest of the simulation (Fig. 5), most peak values of the predicted, instantaneous column cloud fraction have intensities similar to those observed, with a relative error of about $30 \%$ or less.

\section{Aerosol impacts on continental cloud ensembles over Oklahoma}

Sensitivity studies are shown of the impact that biological aerosols could have on cloud properties for a realistic range of scenarios for summertime continental convection over Oklahoma. They are done by modifying the initial aerosol loadings in the control simulation of the ARM-SGP-1997 period validated above (Sect. 4). The control simulation is done with the aerosol-cloud model (Sects. 2, 3.2) and lasts almost a month.

Cloud properties are analysed for all visible clouds (an optical depth $>0.2$ over a $0.5-\mathrm{km}$ layer), except that those vertically below upper-level cirrus (defined in Sect. 4) are excluded from the conditional averaging for some plots. Impacts from IN can be obscured by homogeneously nucleated ice at very high (particle number) concentrations, for deep convection. Averaging, conditionally or otherwise, for vertical profiles displayed spans the entire duration of simulations.

\subsection{Design of sensitivity tests}

The initial loading of insoluble organic aerosols in the continental environment throughout the troposphere over Oklahoma is increased by factors of 10 and 100 in perturbation simulations (the "high and ultra-high bio-aerosol cases", respectively), relative to the control run for ARM-SGP-1997. This augments the concentrations of both active IN and CCN due to insoluble organic aerosols (internally mixed with soluble material) by the same factors, for given conditions of temperature and humidity, at each level in the environment. In all other respects, these simulations are identical to the control run.

Both perturbation simulations are compared with this control run of continental clouds over Oklahoma (ARM-SGP1997). They explore scenarios with biological aerosol concentrations that are higher by similar factors, since biological aerosols (INA bacteria) were assumed to give rise to much of the ice nucleation by the IN-group of insoluble organic aerosols in the background troposphere when the empirical parameterisation was constructed (Phillips et al., 2008).

The perturbation simulations are idealised in the sense that the modified loadings of insoluble organic aerosol do not reflect variability of biological aerosol actually seen over Oklahoma. No field experiments have been done there yet to provide this information. Nevertheless, Lindemann et al. (1982) observed the concentration of viable airborne INA bacteria near the ground to vary, when detectable, by a factor of up to about 200, depending on the type of vegetation and month of summer (only 8 non-zero estimates were measured by Lindemann et al., a very small sample, which was collected mostly during June, so the actual spread of their variable concentrations in the real air near the ground during the year must be much higher than this). Such an enhancement of bio-aerosol 
concentration at a land source would be expected to produce similar fractional changes in concentration downwind, for given atmospheric conditions of dispersion of some flow originating from it. Consequently, the boosting of concentrations by a factor of 100 in the ultra-high bio-aerosol case is plausible as a possible extreme perturbation in the real continental troposphere over Oklahoma due to altered emissions of PBAPs from the ground.

\subsection{Impacts on properties of visible cloud}

Figure 7a shows that the average ice concentration in all visible cloud is increased by between 50 and $100 \%$ at most subzero levels in the ultra-high bio-aerosol case relative to the control run, owing to homogeneous freezing of more numerous cloud droplets. Such homogeneous freezing dominates the domain-wide numbers of ice crystals, as noted above. The homogeneously frozen droplets then sediment through the mixed-phase region (about 4-9 km altitude above the ground; 0 to $-36^{\circ} \mathrm{C}$ ). The sensitivity of the concentration of supercooled cloud droplets diminishes towards the top of the mixed-phase region as noted below, which limits the sensitivity of numbers of droplets homogeneously frozen just above it.

In visible cloud throughout the domain, the peak in number concentration of ice crystals just above the freezing level, at $4-5 \mathrm{~km}$ altitude above the ground, is doubled in the ultrahigh bio-aerosol case, owing to an invigorated H-M process. That peak is located in the H-M generation region, where overall crystal numbers are known to be dominated by the HM process (e.g. Harris-Hobbs and Cooper, 1987; Phillips et al., 2001, 2003, 2005), even on the scale of mesoscale cloud ensembles (Phillips et al., 2007). More ice precipitation and supercooled cloud-liquid are generated in the ultra-high bioaerosol case relative to the control, as noted below, and it rime-splinters there in mixed-phase conditions.

Figure $7 \mathrm{~b}$ shows that in visible cloud without upper-level cirrus vertically above it, an approximate doubling of the average concentration of ice crystals is predicted in the ultrahigh bio-aerosol case relative to the control run. In the high bio-aerosol case, the number concentration of ice crystals is perturbed only slightly relative to the control run over most of the depth (about 4 to $8 \mathrm{~km}$ altitude above the ground) of the mixed-phase region of temperature. Insoluble organic aerosols nucleate only a small fraction of all crystals heterogeneously nucleated, so even a boost by a factor of 100 does not greatly increase the total concentration of heterogeneously nucleated crystals.

Figure 8 shows that the $\mathrm{CCN}$ activity of extra biological particles (assumed to be internally mixed with soluble material) boosts droplet numbers by up to about one order of magnitude in the ultra-high bio-aerosol case relative to the control run. However, towards the top of the mixed-phase region the increase is less than at lower levels, declining to only about $100 \%$, as noted above. Such a reduced sensi- tivity aloft is consistent with the more numerous droplets in the ultra-high bio-aerosol case reducing the supersaturation in deep convective updrafts and quenching in-cloud droplet activation. In-cloud droplet activation in any given updraft becomes more important towards upper levels, due to updraft speeds increasing and droplets being depleted by precipitation (e.g. Phillips et al., 2005). A peak of cloud droplet number in the melting layer coincides with the detrainment of cloud there noted by Phillips and Donner (2006). At that level, insoluble organic aerosol tends to accumulate in the environment during the day to be re-entrained into cloud later on. Little systematic, significant change in droplet concentration is evident for the high bio-aerosol case, since only a small fraction of all droplets in the control run are activated by aerosols containing insoluble organic material.

Figure 9 shows a reduction by up to about $20 \mu \mathrm{m}$ (about $20 \%$ ) in the average size of ice crystals in the mixed-phase region (about 4-9 km altitude above the ground) when upperlevel cirrus is absent in the ultra-high bio-aerosol case relative to the control run. Intensified competition between more ice crystals, for the available vapour during diffusional growth, can cause them to be smaller on average in widespread cloudy regions of weak ascent. This can happen because of the absence of supercooled liquid at low vertical velocities (Phillips et al., 2007), which allows the supersaturation with respect to ice to vary almost inversely with the ice concentration. At most levels in the mixed-phase region, there is little systematic change in the mean size of ice crystals in such regions in the high bio-aerosol case relative to the control run, because the total concentration of heterogeneous crystals is not altered much by an increase of insoluble organic aerosol by only a factor of 10 .

Figure 10 shows a reduction of the mean diameter of cloud droplets by up to $5 \mu \mathrm{m}$ in the ultra-high bio-aerosol case relative to the control run. The reduction is most marked at warm temperatures well below the freezing level. This is consistent with cloud droplets being more numerous and with greater competition for available vapour during their condensational growth. At sub-zero levels another, albeit less influential, factor may be that crystals are more numerous and reduce the supersaturation in mixed-phase conditions in regions of weak ascent, causing less growth of droplets by condensation. Such changes in average droplet size would be expected to perturb the generation of precipitation, either by the warm rain (coalescence of droplets) or ice (e.g. by riming) processes. Perturbed rates of precipitation are indeed found during the simulation (see below).

\subsection{Impacts on meso-scale atmospheric conditions}

Surface precipitation and radiative fluxes are unconditionally averaged over the entire domain. Cloud fraction similarly is plotted for the entire domain. Time-averaging of cloud fraction and fluxes is done over the whole duration of the simulation. 
(a)

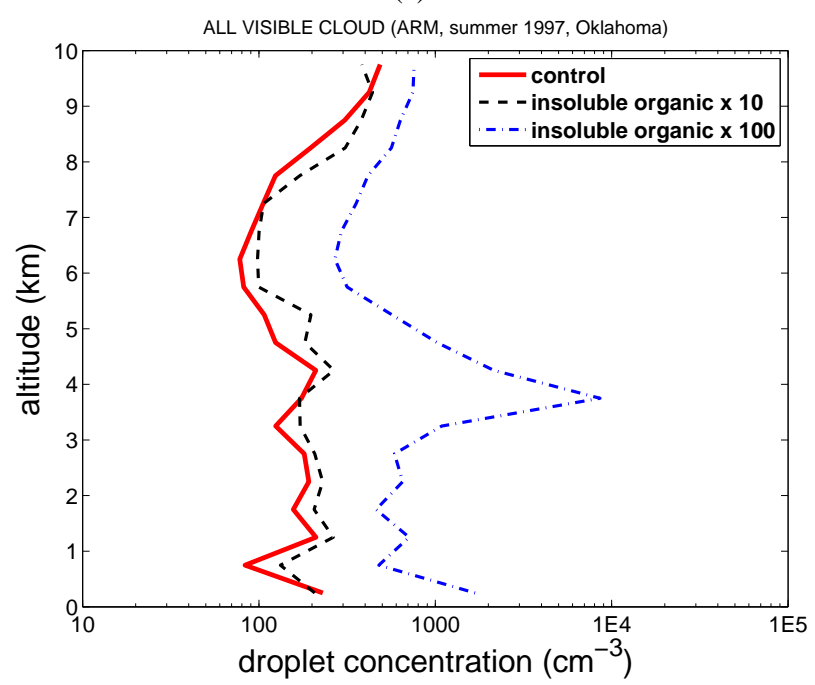

(b)

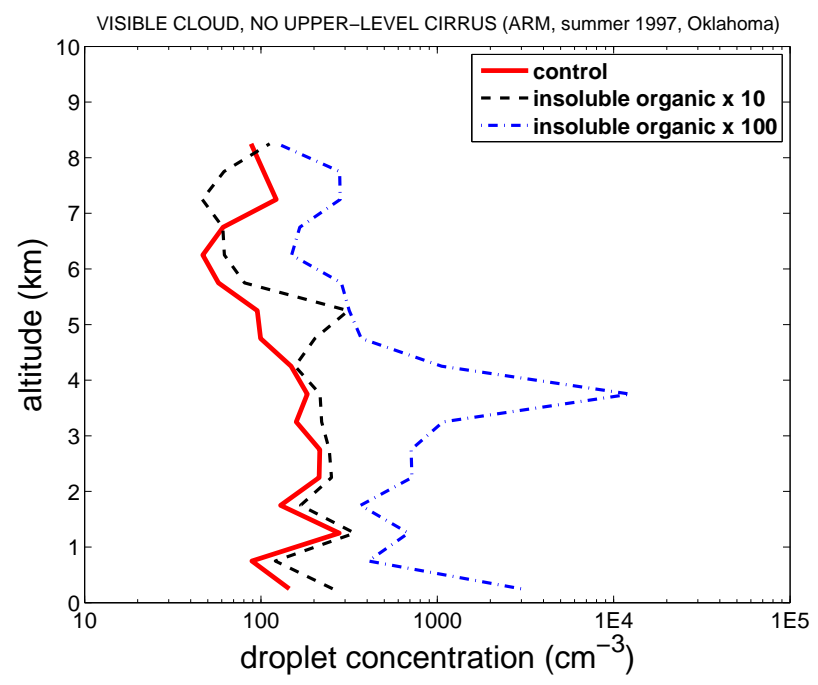

Fig. 8. Droplet concentration plotted and conditionally averaged as in Fig. 7, for visible cloud (a) throughout the whole domain and (b) without upper-level cirrus in the same grid-column.

Mass mixing ratios of cloud-liquid, cloud-ice and snow, unconditionally averaged over the whole domain (not shown), show increases of about $30 \%, 50 \%$ and $10 \%$, respectively at most levels in the ultra-high bio-aerosol case relative to the control run. Graupel and rain show little change, though rain penetrates upwards to altitudes that are about $0.3 \mathrm{~km}$ higher (near $6 \mathrm{~km}$ altitude above the ground) than in the control run. These modest changes may arise from the more numerous ice crystals growing by diffusion of vapour and generaing more snow. Another factor is the slight delay of the onset of the warm rain process (coalescence of cloud droplets) during ascent when the droplets are more numerous and smaller.

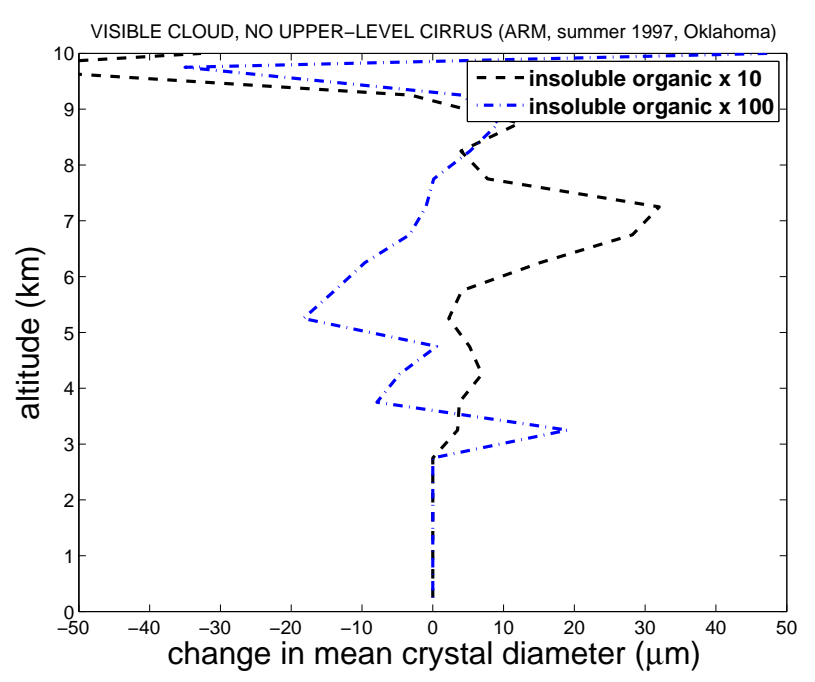

Fig. 9. Change in average profiles of mean size of ice crystals versus height above the ground for high and ultra-high bio-aerosol cases relative to the control run. Conditionally averaging is done over grid-points with visible cloud without any upper-level cirrus above them in The same grid-column (defined in the text) throughout the entire duration of each simulation, as for Fig. 7b.

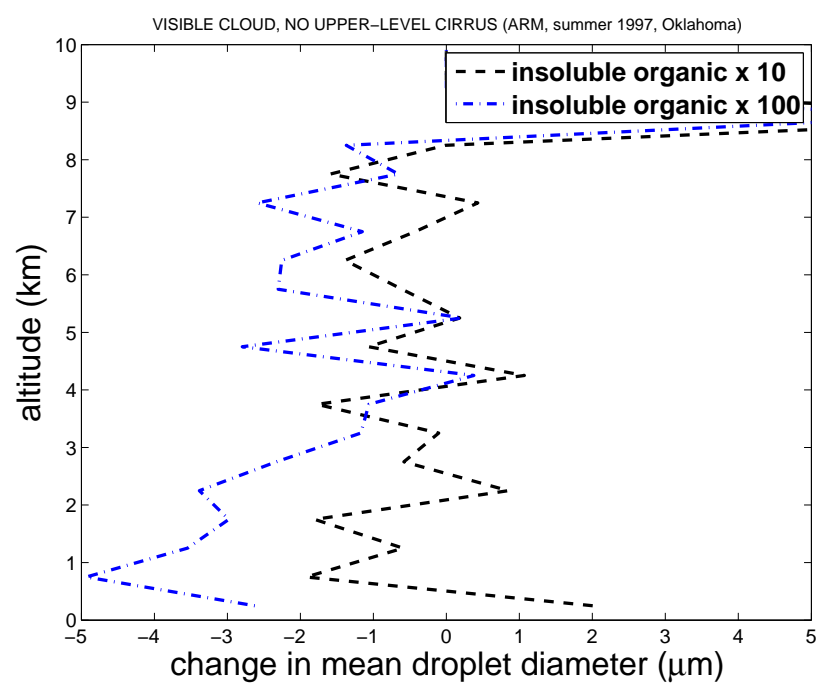

Fig. 10. Change in average profiles of mean droplet size versus height above the ground for high and ultra-high bio-aerosol cases relative to the control run, for visible cloud without upper-level cirrus in the same grid-column (defined in the text), conditionally averaged as for Fig. 9.

Figure 11 shows that the visible cloud fraction is higher by up to 0.02 at most cloudy levels in the ultra-high bio-aerosol case relative to the control run. Regions of weak ascent, especially in the mixed-phase region, contribute most to the cloud cover. The more numerous droplets (e.g. from $\mathrm{CCN}$ activity of PBAPs) are smaller and reduce the warm rain process 


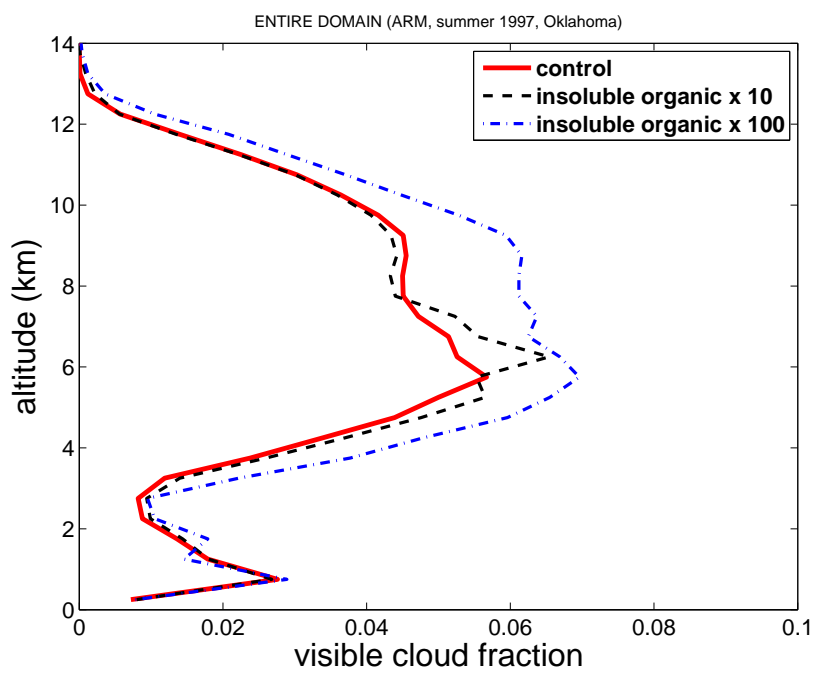

Fig. 11. Fraction of the entire CSRM domain covered by visible cloud (a normal optical depth $>0.2$ over a $500 \mathrm{~m}$ layer) for the control run, and high and ultra-high bio-aerosol cases. Averaging is done unconditionally over the whole duration and domain of each simulation.

(coalescence) of precipitation production in convective updrafts, boosting clouds' life-time and extent in the ultra-high bio-aerosol case. The extra heterogeneous ice from biological IN particles in the ultra-high bio-aerosol case can only partially counteract that effect. It tends to boost precipitation production in mixed-phase clouds via the ice-crystal process, which involves vapour growth of ice, riming and aggregation (Phillips et al., 2003; Lohmann and Feichter, 2005). In summary, PBAPs' CCN activity is more important than their IN activity for the response of cloud fraction in these particular runs. There is little systematic change in cloud fraction in the high bio-aerosol case relative to the control run, as expected from the weakness of the change in overall IN and $\mathrm{CCN}$ activity of all aerosol particles.

Figure 12 shows that the downward component of the shortwave flux near the ground (averaged over the whole domain) is reduced by over $10 \mathrm{~W} \mathrm{~m}^{-2}$ in the ultra-high bioaerosol case relative to the control run. Partly, there is more reflection of incoming solar radiation by clouds that are more extensive and reflective at most levels, due to more numerous and smaller ice crystals and droplets. This type of impact can be caused by modified loadings of any species of aerosol, not only of insoluble organic aerosol coated with soluble material. Figure 13 shows little systematic response of the downward longwave flux at the ground, although it is about $5 \mathrm{~W} \mathrm{~m}^{-2}$ higher at levels in the mixed-phase region in the ultra-high bio-aerosol case relative to the control run. Radiative fluxes in the high bio-aerosol case show little systematic change at all levels relative to the control run.

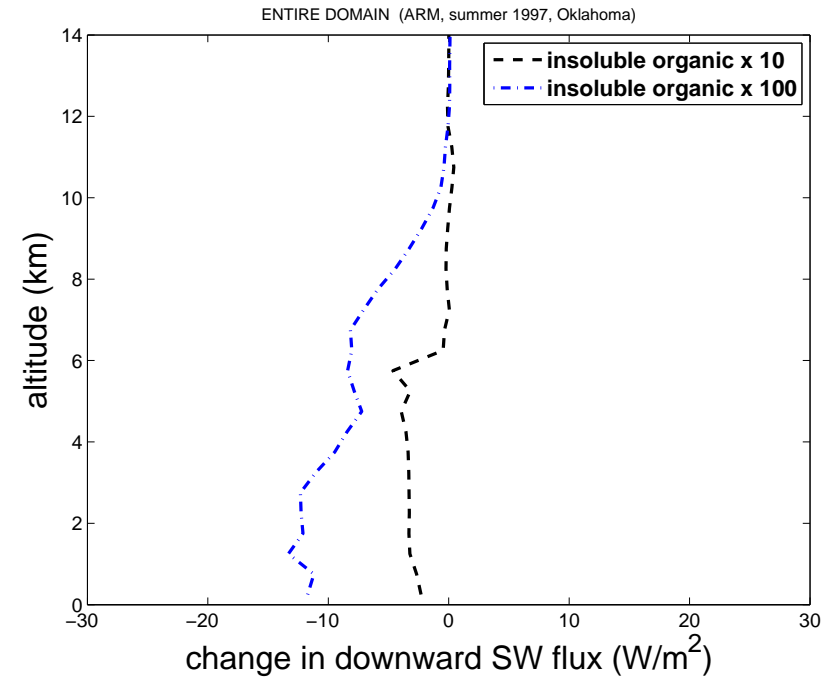

Fig. 12. Change in domain-averaged profiles of the downward component of the shortwave flux versus height above the ground for high and ultra-high bio-aerosol cases relative to the control run. Averaging is done unconditionally over the whole duration and domain of each simulation.

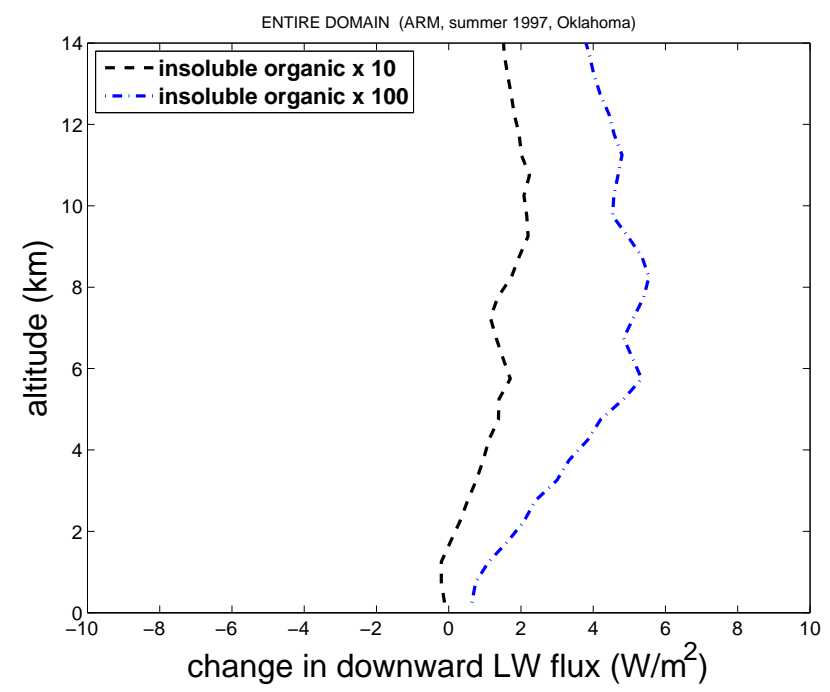

Fig. 13. Change in domain-averaged profiles of the downward component of the longwave flux versus height above the ground for high and ultra-high bio-aerosol cases relative to the control run. Averaging is done unconditionally over the whole duration and domain of each simulation.

Figure 14 shows the accumulated surface precipitation. It is suppressed slightly by up to $2 \mathrm{~mm}$ (about $10 \%$ ) during the first week of deep convection in the ultra-high bioaerosol case relative to the control run. That is consistent with higher concentrations of droplets, from extra biological particles acting as $\mathrm{CCN}$, tending to reduce the efficacy of the warm rain process. The intensity of in-cloud ascent 


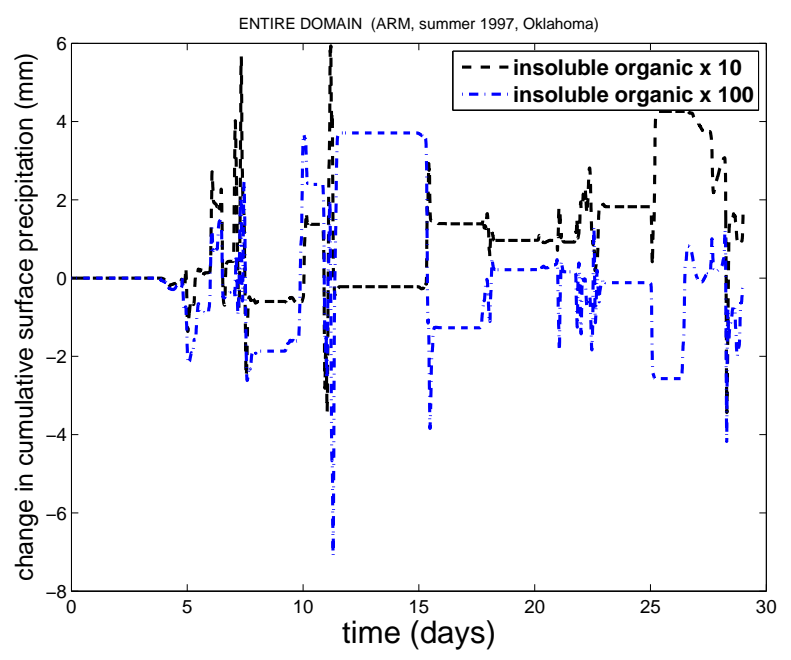

Fig. 14. Change in accumulated surface precipitation (mm) averaged over the entire domain for high and ultra-high bio-aerosol cases relative to the control run, as a function of time (days after start of simulation).

is mostly unaltered (see histograms below). After the first week of deep convection, the sign of the difference between the ultra-high bio-aerosol case and control run alternates, as it must do for the total precipitation over long periods to balance the prescribed large-scale advection of moisture into the domain. The difference is always between about -3 and $3 \mathrm{~mm}$ (between 2 and 10\%). At the end of the month-long period simulated, there is little change in accumulated precipitation. Partly, this is an inevitable consequence of the design of any CSRM experiment with cyclic boundary conditions, which must omit the feedback from convection onto the large-scale advection. Finally, there is little change in precipitation in the high bio-aerosol case, which involves less change of atmospheric loadings of insoluble organic aerosol.

Figure 15 shows the domain-wide statistics of vertical velocity, $w$, for regions of ascent and descent $(|w|>0.1 \mathrm{~m} / \mathrm{s})$. There is little sensitivity of the rate of ascent, with perturbations of $w$ being of the order of about $1 \%$ in the ultra-high bio-aerosol case relative to the control run. However, the strongest convective downdrafts $(|w|>1 \mathrm{~m} / \mathrm{s})$ are up to about $10 \%$ faster in the ultra-high bio-aerosol case. This is consistent with the higher numbers of cloud-particles, from the $\mathrm{CCN}$ and IN activity of bio-aerosols, accumulating aloft and augmenting the rates of evaporative and sublimational cooling, intensifying downdrafts (e.g. Khain et al., 2004; Lee et al., 2008).

\section{Conclusions}

A framework has been described for modeling the effects of biological particles on clouds. It utilises the empirical pa- (a)

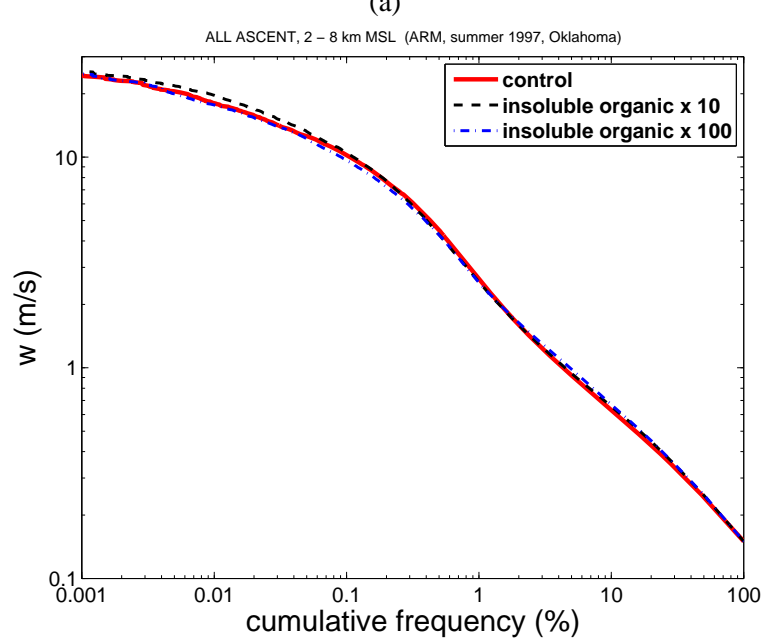

(b)

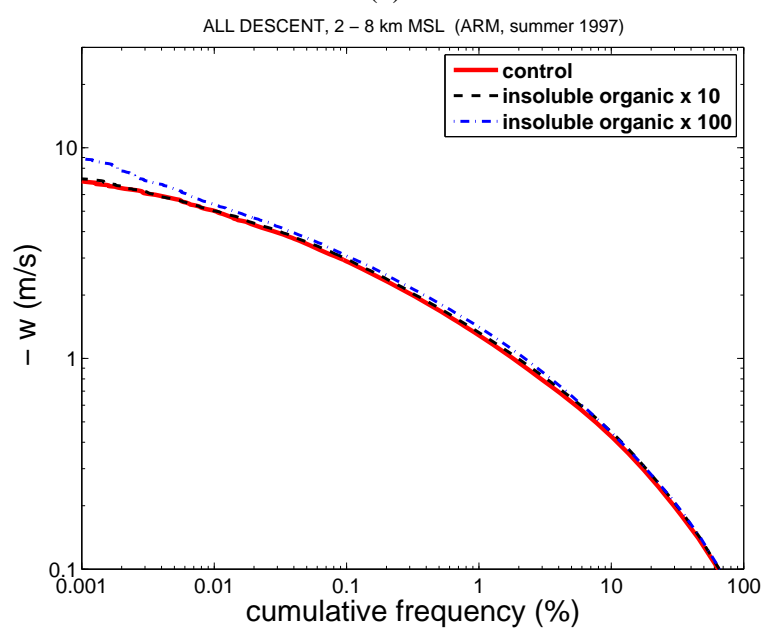

Fig. 15. Cumulative frequency distribution of vertical velocity, $(|w|>0.1 \mathrm{~m} / \mathrm{s}$ ), for all ascent (upper panel, a) and descent (lower panel, b) across the whole domain between 2 and $8 \mathrm{~km}$ altitude above the ground for the ARM cases from Oklahoma (summer 1997), throughout the entire duration of each simulation.

rameterisation of heterogeneous nucleation of ice by multiple chemical species of aerosol (Phillips et al., 2008). The empirical parameterisation and a semi-prognostic aerosol component have been implemented into our CSRM, which has double-moment bulk microphysics. It now treats the twoway aerosol-cloud-radiation interaction. This aerosol-cloud model represents the activation of ice crystals and droplets by insoluble organic aerosols internally mixed with soluble material, such as PBAPs.

One month of deep convection over Oklahoma (ARMSGP-1997) has been simulated with the model. It involves varying wind shears and thermodynamic conditions. This simulation of continental clouds compares adequately with available ground-based, aircraft and satellite observations (Sect. 4). 
Robustness of the aerosol-cloud model's accuracy has been demonstrated by similarly validating its simulations of two other contrasting cases with maritime aerosol conditions in Appendix A. They are the Tropical Ocean Global Atmosphere Coupled Ocean-Atmosphere Response Experiment (TOGA-COARE) and the Kwajalein Experiment (KWAJEX), and have not been used for any biological sensitivity studies here.

Predicted number concentrations of cloud droplets and ice particles each differ by less than about half an order of magnitude from aircraft observations for all three simulations of continental (ARM-SGP-1997) and maritime (KWAJEX, TOGA-COARE) convection. They are all performed with the same version of the model. Aerosol and thermodynamic inputs are specified realistically for each run, with profiles of sulphate aerosol loading being constrained by in situ observations. Acuity of validation of concentrations of ice and cloud droplets is rather limited in the ARM-SGP-1997 simulation, as the aircraft observations were from elsewhere in the USA. However, acuity of validation is much higher for the maritime simulations (Appendix A). For KWAJEX, predicted concentrations of ice particles and of droplets each agree to within a factor of about two with aircraft observations also from KWAJEX. The same applies for droplet concentrations both predicted for, and observed in, TOGACOARE.

Moreover, all radiative fluxes have errors of less than $14 \%$ in all three simulations. This is consistent with predicted concentrations of ice and droplets being reasonable in ARMSGP-1997, because the predicted radiative fluxes, especially in the shortwave, are sensitive to these concentrations and are related to them realistically in the model. For instance, the generalised effective size of ice particles is an input to the model's radiation scheme, for simulation of cloud radiative properties (e.g. albedo), and is inferred from predicted concentrations with a look-up table, as described by Phillips et al. (2007). This effective size of ice is validated for the KWAJEX simulation here (Appendix A), in addition to the ice concentration. In the aerosol-cloud model, concentrations of cloud-particles govern their mean and effective sizes, their rates of sedimentation, and hence, both the extent and radiative properties of clouds (Sect. 2), as in nature. Adequate accuracy is obtained in all three simulations partly because the known and empirically quantified mechanisms for initiation of ice and liquid are represented in detail.

Elevated loadings of biological aerosol (e.g. INA bacteria) are represented by boosting the environmental concentration of insoluble organic aerosol that initialises the simulation of continental convection (ARM-SGP-1997). The control run was validated above (Sect. 4). The main conclusions are summarised as follows:

- The average concentration of ice crystals is increased by up to about $100 \%$ in the ultra-high bio-aerosol case within cloudy regions relative to the control run. Het- erogeneous ice nucleation, the H-M process and homogeneous freezing of supercooled cloud droplets are all intensified. The domain-wide average concentration of ice crystals in the H-M region is approximately doubled due to an invigorated H-M process of ice multiplication, as ice precipitation and supercooled cloud-liquid are more abundant. Sub-saturation with respect to water originates at low vertical velocities from extra ice crystals' vapour growth (e.g. Phillips et al., 2007) and evaporates away all cloud-liquid. This must limit biological ice nucleation in cloudy regions of weak ascent, quenching some of the sensitivity.

- Cloud droplets are more numerous (by a factor of at least about 2), with the least sensitivity near the top of the mixed-phase region, and are smaller on average (by a few microns) in the ultra-high bio-aerosol case relative to the control run. They mostly arise from the $\mathrm{CCN}$ activity of extra insoluble organic particles. Such changes perturb the precipitation production, delaying it initially as expected from their smaller size, and thus boosting the mass of supercooled cloud-liquid aloft.

- The downward shortwave flux in the lower troposphere is reduced appreciably (by about $10 \mathrm{~W} \mathrm{~m}^{-2}$ or $5 \%$ ) in the ultra-high bio-aerosol case relative to the control run. This arises from extra reflection of incoming solar radiation by clouds that are more extensive and have more numerous and smaller cloud-particles, which enhances their albedo. There is a slight increase (about $1 \mathrm{~W} \mathrm{~m}^{-2}$ ) in the downward longwave emission to the surface. The flux changes would tend to cool the land surface, if sustained.

- Surface precipitation is perturbed by up to about $10 \%$ during the first week or so of deep convection in the ultra-high bio-aerosol case relative to the control run, with a slight reduction initially. This is partly due to the more numerous, smaller droplets from $\mathrm{CCN}$ activity of the extra bio-aerosols in the perturbation simulation, which inhibits the warm rain process (coalescence of droplets to form raindrops). Also, vapour growth of more numerous ice crystals produces more snow in the ultra-high bio-aerosol case.

- The most vigorous downdrafts are faster in the ultrahigh bio-aerosol case than in the control run.

In order to influence cloud properties and mesoscale atmospheric conditions substantially, it is found that the insoluble organic loading must be increased by at least a factor of about 100 beyond its usual continental values. One reason is that an increase by the same factor of insoluble organic aerosol in, say, the background free troposphere would boost the total number of active IN from all aerosol groups (dust, soot, biological) by only a factor of about six. This is much less than the boosting of IN concentrations commonly seen from 
intense emissions of dust (e.g. DeMott et al., 2003b; Phillips et al., 2007) or soot. It is partly why the impacts found here, on clouds from ice nucleation by extra insoluble organic particles, such as biological aerosols, are quite modest. Indeed, dust/metallic aerosols are seen to cause most of the heterogeneously nucleated crystals of ice in the background troposphere, from field observations with mass spectrometry analysis of real IN particles (Sect. 2.4). These observations underpin the empirical parameterisation.

Yet the results shown here suggest that emissions of biological aerosols into the atmosphere, if sufficiently intense, would influence meteorological conditions, such as wetness and temperature, near the surface. Sometimes they might even dominate the overall rates of heterogeneous ice nucleation locally, perhaps downwind from land sources. This opens the question of whether there is a weak feedback of some kind, similar to that hypothesized by Sands et al. (1982), between emissions of biological aerosols, clouds and meteorological conditions. For instance, growth rates of INA bacteria on leaves (Sect. 2.4) are known to be correlated with two factors: (1) surface air temperature, exponentially (e.g. between 2 and $32^{\circ} \mathrm{C}$; see Caristi et al., 1991); and (2) the drying period after precipitation has fallen at the ground. Average concentrations of airborne bacteria were seen to increase exponentially with temperature in the UK by Harrison et al. (2005), and to depend on average wind speed. Turbulence and convection in the planetary boundary layer (PBL) may influence emissions. The present study suggests that biological aerosols, if sufficiently numerous, can influence the intensity of precipitation and fluxes of incident solar radiation at the surface, which would be expected to modify both factors in nature.

Arguably, the same factors important to the aerosolization of bacteria would also influence that of any other plantassociated (or leaf litter-associated) INA organism (e.g. fungal material). Thus, if weak feedbacks between PBAP emission and alteration of meteorological conditions exist, these are not necessarily restricted to INA bacteria. Naturally, different INA organisms must have different permissible ranges of temperature and wetness for their growth in the biosphere. Changes in surface temperature could induce a biological response, with changes in community composition and growth dynamics of INA species ejected into the atmosphere.

Frozen fractions of various types of INA bacteria plotted above (Fig. 1, Sect. 2) vary by up to about 5 orders of magnitude at a given temperature. Similarly, frozen fractions among strains of $P$. syringae were seen by Hirano et al. (1985) to vary log-normally over more than 6 orders of magnitude at a given temperature. Hence, the precise types of ice-nucleating PBAP emitted may be important for any impacts on cloud ensembles in nature, in addition to their airborne concentrations. Any changes in community composition of INA species could indeed be influential.

Biological particles can act as $\mathrm{CCN}$ and the impact from their IN activity can be amplified by the H-M process of ice particle multiplication $\left(-3\right.$ to $-8^{\circ} \mathrm{C}$ ) (e.g. Möhler et al., 2007). Such processes are treated by our aerosol-cloud model (Sect. 2) and occur in simulations shown here. Both the H-M process and the CCN activity of sub-micron insoluble organic aerosols were found to be boosted in the ultrahigh bio-aerosol case relative to the control. However, uncertainty is associated with treating the size distribution of PBAPs, and hence, also their CCN activity. Firstly, the critical supersaturation of droplet activation of any PBAP depends on its size, which influences the mass of its soluble coating. Matthias-Maser and Jaenicke (1995) observed size distributions of PBAPs to have a dominant peak with a modal diameter of about 0.2 microns, as assumed here (Table 1). But the natural variability of PBAP size distributions, arising from fluctuations in the abundance of individual types of biological particle (Sect. 1), has only just begun to be charted in the troposphere. Secondly, the critical supersaturation of droplet activation by a PBAP is very sensitive to the assumed soluble mass fraction for its coating (assumed to be sulphate in the model, which implicitly treats all the many soluble compounds that may coat actual PBAPs, including soluble organic species). The observed value (0.8) used in the present study was selected because of the general lack of other relevant estimates in the literature.

Both the soluble mass fraction and size distribution of biological aerosols are important for the sensitivity test presented here. Both are uncertain and few observations constrain them. For instance, if the sensitivity test were redone with a lower value for the soluble mass fraction $(0.1$ instead of 0.8) of biological particles in all runs and a broader spectral width of their size distribution (MJ95), the outcome would be quite different. The droplet number concentration would be increased by less than a factor of 2 at most levels, the cloud fraction would be changed appreciably above (a reduction by about 0.01 ) but not below the freezing level, and the solar insolation at the ground would be much less sensitive, for the same increase in bio-aerosol loading by a factor of 100. Yet this 100 -fold boost was chosen rather arbitrarily, in view of the paucity of field observations (Sect. 5.1). Applying a greater boost (e.g. a factor of 500) to the PBAP loading should give results qualitatively similar to those noted above (Sect. 5) for a lower soluble mass fraction.

In nature, a minority of biological particles have giant sizes of about 10 microns or more in diameter (e.g. pollen and their fragments, large multi-cellular biological fragments). They may sometimes accelerate coalescence by acting as giant $\mathrm{CCN}$ and forming large drops as soon as they activate (Möhler et al., 2007). This effect from super-micron PBAPs is not explicitly treated in our model. But equally, it was shown that the paucity of (ultra-)giant CCN generally makes their influence minimal when clouds are far from the threshold for the onset of precipitation, in the modeling study by Feingold et al. (1999). Deep convection that is substantially precipitating would seem to belong to that category. There is still uncertainty about how, and what types of, clouds would 
be influenced by such super-micron PBAPs.

The diverse pathways by which overall ice concentrations are modified by insoluble organic loadings, in the sensitivity tests presented here, include these key ones: (1) biological nucleation of ice by PBAPs' IN activity; and (2) homogeneous freezing of droplets activated by PBAPs' CCN activity. Relative contributions to the overall sensitivity from both pathways of ice initiation have not been determined precisely yet with the model. Both mechanisms are clearly boosted in the ultra-high bio-aerosol case, and both can influence the H-M process of ice multiplication. Also, PBAPs' CCN activity can modify the warm rain process and the abundance of supercooled cloud-liquid aloft. Overall crystal numbers in deep convective ensembles over the tropical Pacific were found to be more sensitive to any given fractional change in concentration of CCN than to that of IN (Phillips et al., 2007). Consequently, when modeling the influence of biological aerosols generally, it seems vital to treat the $\mathrm{CCN}$ activity of the most numerous PBAPs at small sub-micron sizes.

The results about potential impacts from biological aerosols depend on the empirical parameterization of ice nucleation. There is significant uncertainty in its representation of ice nucleation by biological and other insoluble organic particles (Sect. 2.4; Phillips et al., 2008). The fraction of heterogeneous crystals of ice nucleated by INA bacteria and other biological aerosols has scarcely been observed systematically in the free troposphere, owing to past limitations in the chemical analysis of residual particles from heterogeneous crystals sampled there. It is not certain yet whether the dominant contribution to biological ice nucleation generally in the real troposphere is mostly INA bacteria or one of the other types of PBAP noted above, like plant matter (Sect. 1). INA bacteria were estimated to contribute about half of the active IN from the insoluble organic group in the empirical parameterisation's construction. But this estimate is uncertain and the other half was assumed to originate from IN activity of other biological or non-biological organic aerosols. Consequently, both sensitivity tests documented here are to be interpreted broadly as portraying the impacts from extra ice-nucleating PBAPs generally, sufficient to raise concentrations of the active IN and $\mathrm{CCN}$ within the insoluble organic group by factors of 10 and 100 .

There are also uncertainties in treating the ice microphysics, as noted by Phillips et al. (2007). As with most other bulk microphysics schemes currently, the observed dependencies of the shape-parameter of the size distribution of ice particles on their mean size, and of their bulk density and axial ratio on size and temperature (e.g. Pruppacher and Klett, 1997; Heymsfield et al., 2002b), are neglected when treating microphysical conversions. Nonetheless, when inferring the generalised effective size, some of these dependencies, such as on axial ratio, have been accounted for in the aerosol-cloud model (Sect. 2).
Finally, the vigour and depth of convection in the ARM cases at Oklahoma tended to obscure the atmospheric effects from biological (heterogeneous) ice nucleation in the present study. This is due to the predominance of homogeneous freezing and the warm rain process in deep convective clouds (e.g. Phillips et al., 2001, 2002, 2005). By contrast, light precipitation from mixed-phase nimbostratus, which is less deep, can be highly sensitive to IN concentrations generally (e.g. Phillips et al., 2003). The precipitation is formed by the ice process, which involves vapour growth of crystals that sediment and then rime or aggregate together. Such horizontally extensive mixed-phase clouds are ubiquitous at mid- to high-latitudes. Land sources of biological aerosols are common there.

Future modeling work may focus on simulation of mixedphase clouds that are less deep, so as to isolate the effects from biological (heterogeneous) ice nucleation. Inclusion of an interactive land component would allow the response of air temperature near the surface to be assessed. Ensembles of simulations would increase confidence in the statistical significance of results.

The modeling framework proposed here is apt for inclusion of a component treating the growth of INA bacteria on leaves in the biosphere (e.g. Caristi et al., 1991). Bacterial cells could become a separate aerosol species in the model. In the future, more extensive, accurate and correlated field measurements of the occurrence and nucleating ability of multiple species of biological IN may be easily assimilated into the framework, improving model accuracy. In particular, analysis of the composition of biological residual particles from crystals of ice (e.g. Cziczo et al., 2004) may improve the empirical parameterisation. Future field measurements of INA bacteria and coincident meteorological observations may provide better cases for simulation with advanced cloud models. Clearly, the size distribution of PBAPs and their soluble coatings are key quantities to observe in future field studies. An inter-disciplinary focus will be needed (Morris et al., 2008b).

In summary, airborne biological aerosols, such as INA bacteria, if present at sufficiently high concentrations, are shown here to modify the extent and properties of clouds. Solar insolation and precipitation near the ground are then altered. These are quantities known to determine bacterial growth and may influence production of certain other biological aerosols also. The potential existence of some type of weak feedback between biological nucleation of ice and droplets, clouds and natural emissions of biological particles from the ground merits further exploration. 
(a)

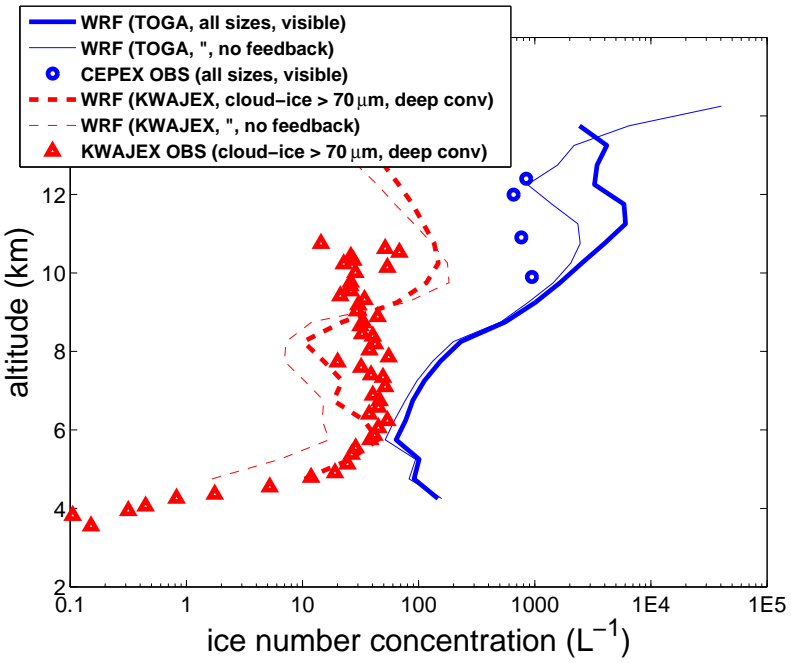

(b)

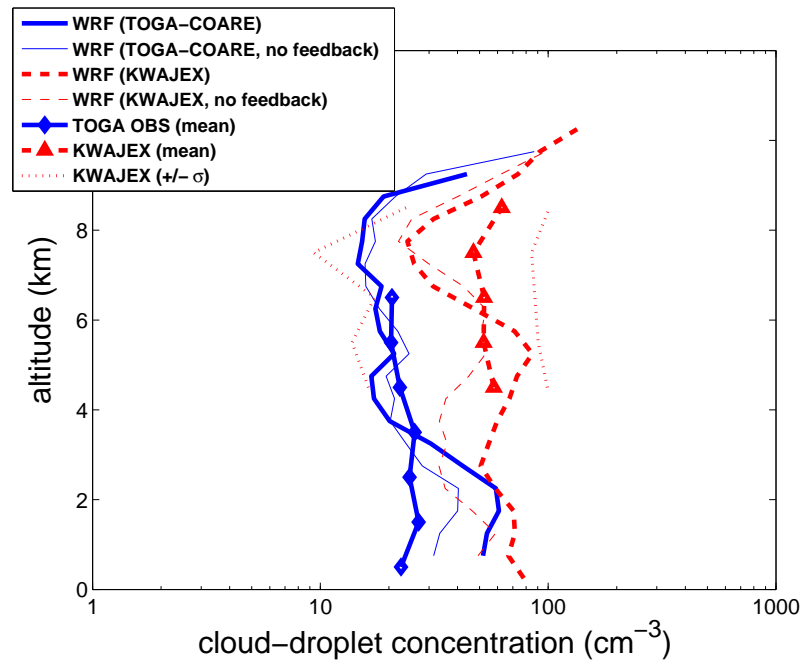

Fig. A1. Predicted number concentrations ("WRF") of (a) cloud ice predicted for TOGA-COARE and KWAJEX, compared with CEPEX and KWAJEX aircraft observations respectively; and (b) the predicted and observed number concentrations of cloud droplets for TOGA-COARE and KWAJEX. The predicted vertical profiles are obtained by averaging conditionally over regions of visible (TOGA-COARE) and highly visible (KWAJEX) cloud, as defined in the text, during the entire simulated periods.

\section{Appendix A}

\section{Validation of simulations of maritime convection}

Two tropical oceanic cases were simulated and validated by Phillips et al. (2007) with an earlier version of our doublemoment CSRM. These are the Tropical Ocean Global Atmosphere Coupled Ocean-Atmosphere Response Experiment (TOGA-COARE) and the Kwajalein Experiment (KWAJEX). TOGA-COARE took place at the western edge of the
Pacific ocean, while KWAJEX occurred in a more remote part of the Pacific (Kummerow et al., 2000). Predicted number concentrations of cloud-ice particles and cloud droplets were compared with aircraft observations.

Here, both maritime cases are simulated again with the latest version of the model described and validated above (Sects. 2, 4). Both simulations are compared with the same observational data from KWAJEX and TOGA-COARE, including some new cloud-related and thermodynamical statistics in the validation. Following Phillips et al. (2007), the predicted properties of cirrus for TOGA-COARE are compared with observations from the Central Equatorial Pacific Experiment (CEPEX; McFarquhar et al., 1999), in view of the lack of flights above the freezing level during TOGACOARE. Note that these maritime simulations (KWAJEX, TOGA-COARE) are not used for any biological sensitivity tests anywhere in the present paper.

A description of both maritime cases is given by Phillips et al. (2007). Their aerosol conditions were very different from those noted above for the land cases at Oklahoma. TOGACOARE (20-25 December 1992) was a case of vigorous deep convection with maximum cloud-top levels of about 12-14 km above MSL (Ciesielski et al., 1997), while KWAJEX (17-31 August 1999) entailed weaker convection with cloud-tops usually below the altitude of $10 \mathrm{~km}$ above MSL (Heymsfield et al., 2002b). The TOGA-COARE case displayed a very strong shear of the horizontal mean flow. Both tropical Pacific cases involve less intense precipitation and have a higher relative humidity than for the ARM-SGP-1997 case.

\section{A1 Experimental setup}

The model set-up is as described above (Sect. 3.2). The CSRM is initialised with observed profiles of temperature and humidity from TOGA-COARE (Ciesielski et al., 1997) and from M. Zhang for KWAJEX. Convection is maintained with tendencies for the large-scale advection of humidity and temperature provided by Ciesielski et al. (1997) and M. Zhang at Stony Brook University for TOGA-COARE and KWAJEX, respectively.

Profiles of aerosol loading for all species were provided by the GFDL GCM noted above. However, the loading of sulphate aerosol is critical for the overall CCN concentration. Its value near the surface predicted by the global model (GCM) was much lower than seen from ship observations in the tropical Pacific during the western-most equatorial transect (Leg 5) of the 3rd Soviet-American Gas and Aerosol (SAGA 3) experiment (Clarke and Porter, 1993) in 1990, at the same latitude ( -2 degrees) and season (winter) as TOGA-COARE, but much further to the east. There a mass concentration of ammonium sulphate of about $0.5 \mu \mathrm{g} \mathrm{m}^{-3}$ at the surface was observed. Although Leg 5 of SAGA 3 was at the same longitude as Samoa, in a more remote part of the tropical Pacific than TOGA-COARE, Clarke and Porter 
Table A1. Longwave and shortwave fluxes at the top of the atmosphere (TOA) and ground (SFC) for upward and downward components respectively for the two extra cases described in Appendix A. Simulations with the aerosol-cloud model (Sect. 2) with the feedback from clouds onto environmental aerosol fields are denoted by WRF. Percentage errors are given in parenthesis. Predicted fluxes displayed are averaged over the entire domain and duration of the simulation, except that the first 2 days are omitted for spin-up of the model.

\begin{tabular}{llllll}
\hline \multirow{2}{*}{ Case } & $\begin{array}{l}\text { Simulation/ } \\
\text { observations }\end{array}$ & \multicolumn{3}{l}{ SHORTWAVE FLUX $\left(\mathrm{W} \mathrm{m}^{-2}\right)$} & \multicolumn{2}{l}{ LONGWAVE FLUX $\left(\mathrm{W} \mathrm{m} \mathrm{m}^{-2}\right)$} \\
\cline { 3 - 6 } & & $\begin{array}{l}\text { TOA } \\
\text { upwards }\end{array}$ & $\begin{array}{l}\text { SFC } \\
\text { downwards }\end{array}$ & $\begin{array}{l}\text { TOA } \\
\text { upwards }\end{array}$ & $\begin{array}{l}\text { SFC } \\
\text { downwards }\end{array}$ \\
\hline \multirow{2}{*}{ TOGA-COARE } & WRF & $200.4(-2 \%)$ & $125.19(9 \%)$ & $165.1(-1 \%)$ & $423.26(-1 \%)$ \\
& Observed (Minnis/IMET) & 208.2 & 115.0 & 167.1 & 427.7 \\
& Observed (ISCCP) & 204.5 & 146.2 & 167.3 & 458.6 \\
KWAJEX & WRF & $132.0(4 \%)$ & $226.6(-13 \%)$ & $224.8(-4 \%)$ & $423.9(0.2 \%)$ \\
& Observed & 127.5 & 259.7 & 234.6 & 423.1 \\
\hline
\end{tabular}

showed that the variability of sulphate aerosol was primarily latitudinal. Hence, this ship observation was assumed to apply to TOGA-COARE also, implying a factor of 2 that multiplies the GCM profile of sulphate loading throughout the troposphere so as to match it with the observation at the surface $\left(0.5 \mu \mathrm{g} \mathrm{m}^{-3}\right)$. By contrast, during Leg 5 , the ship observation of sulphate aerosol at the same latitude as KWAJEX was the same (about $0.3 \mu \mathrm{g} \mathrm{m}^{-3}$ ) as predicted by the GCM, so no such adjustment was needed.

As justified by Phillips and Donner (2006), a fixed increment was added to the input of cloud-ice mixing ratio for the radiation code throughout the entire simulations of TOGACOARE $(2.7 \mathrm{~g} / \mathrm{kg}$ between 5.5 and $8.5 \mathrm{~km})$ and KWAJEX $(1.8 \mathrm{~g} / \mathrm{kg}$ between 5.2 and $8.2 \mathrm{~km})$. This was necessary so as to account for the inferred advection of non-precipitating cloud into the simulated region. Observations were insufficient to characterize these cloud-decks, inferred from observed values of the outgoing longwave radiation flux. The values and altitude of these increments were selected so as to match the predicted and observed fluxes of radiation at TOA in the first few hours of both simulations. The actual prognostic variables were left unchanged.

\section{A2 Cloud properties}

Figure A1a shows the vertical profiles of predicted number concentrations of cloud-ice particles and cloud droplets, conditionally averaged over visible and highly visible cloudy regions (defined above) in TOGA-COARE and KWAJEX respectively. The sampling criteria differ because of different flight strategies.

For KWAJEX, the prediction of 2D-C number concentration of cloud ice $(>70 \mu \mathrm{m})$ averaged over all flight days has a peak at the correct altitude (about $6 \mathrm{~km} \mathrm{MSL}$ ) and agrees with the observed value to within a factor of about two at most observational levels. This peak is caused by the H-M process. Accuracy is improved by inclusion of the feedback from clouds onto the aerosol fields.
Also shown in Fig. A1a is the total ice crystal concentration inferred from CEPEX aircraft data and predicted for TOGA-COARE. The observed ice concentration is about half an order of magnitude lower than the prediction at most observational levels above about $10 \mathrm{~km} \mathrm{MSL}$ altitude, where ice crystals are generated by homogeneous freezing of cloud droplets or CCN. Exact agreement is not to be expected because the CCN concentration differed between TOGACOARE and CEPEX, and since convective activity was more quiescent during CEPEX.

Figure A1b shows the predicted and observed number concentrations of cloud droplets. In TOGA-COARE, 10 flight days during December 1992 by the Electra aircraft provided the data. Relative errors in the predicted droplet concentrations are less than about $50 \%$ at levels where a comparison is possible in KWAJEX and TOGA-COARE. Sources of inaccuracy include treatments of the size distribution and mass concentrations of (e.g. sulphate) aerosol.

Figure A2 shows the generalized effective size and mean sizes of ice crystals. The generalised effective size determines the radiative properties of glaciated clouds. Its profile has errors of less than $90 \%$ at all levels, similar to, or less than, those documented by Phillips et al. (2007) for the earlier version of the model. There is good agreement between mean sizes of ice crystals predicted in TOGA-COARE and observed in CEPEX above $12 \mathrm{~km}$ MSL, with a high bias of about $10 \mu \mathrm{m}$ below this level.

\section{A3 Thermodynamical, radiative and precipitation statistics}

Figure A3 shows that the mean errors in temperature and vapour mixing ratio are less than about $5 \mathrm{~K}$ and $1 \mathrm{~g} / \mathrm{kg}$ at all levels.

Validation of simulated radiative fluxes is shown in Table A1. For TOGA-COARE, two sets of observed radiative fluxes were obtained from: (1) the International Satellite Cloud Climatology Project (ISCCP) (Zhang et al., 1995; 
(a)

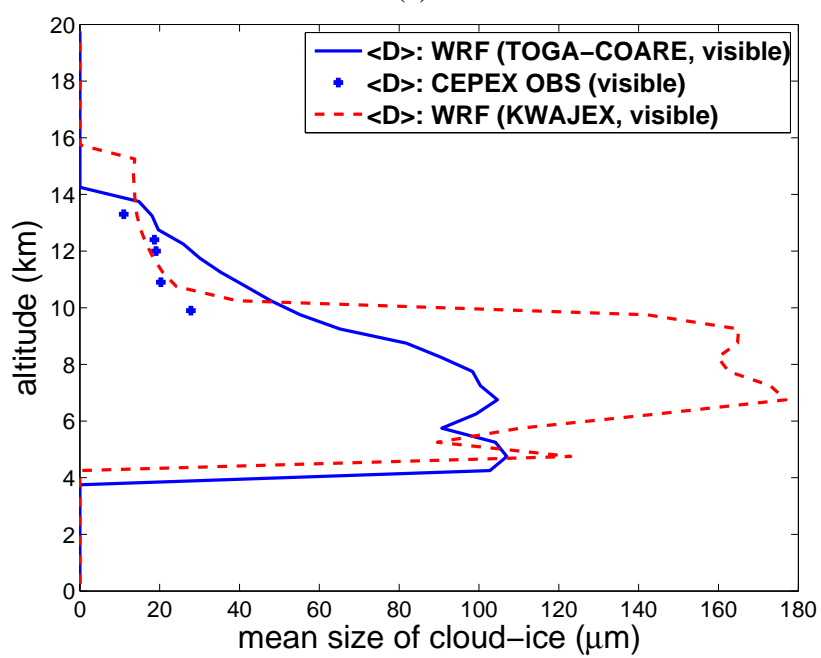

(b)

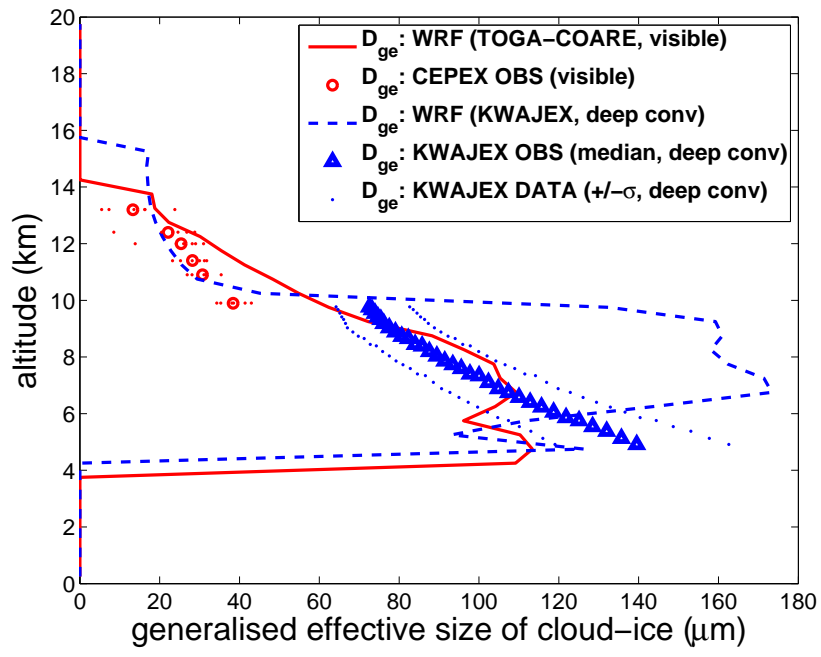

Fig. A2. Predicted ("WRF") (a) mean size and (b) generalised effective sizes of cloud ice predicted for TOGA-COARE and KWAJEX, compared with CEPEX and KWAJEX aircraft observations. Conditional averaging is done as in Fig. A1.

Rossow and Zhang, 1995); and (2) from P. Minnis at NASA Langley (e.g. Minnis et al., 1995) for the top of the atmosphere and from Improved Meteorology (IMET) buoy data (Weller and Anderson, 1996; Burks, 1998) for the surface. They are used for validation at the top of the atmosphere and surface respectively. For KWAJEX, observed radiative fluxes were obtained from the project website. Relative errors in predicted net radiative fluxes at TOA are all less than $4 \%$ in the short- and long-wave for both cases. At the surface, relative errors are less than about $10 \%$ and $1 \%$ in the short- and long-wave respectively. They are much less than those of the measurement uncertainty (about 25 and $10 \%$ in the short- and long-wave, from alternative surface estimates in TOGA-COARE).
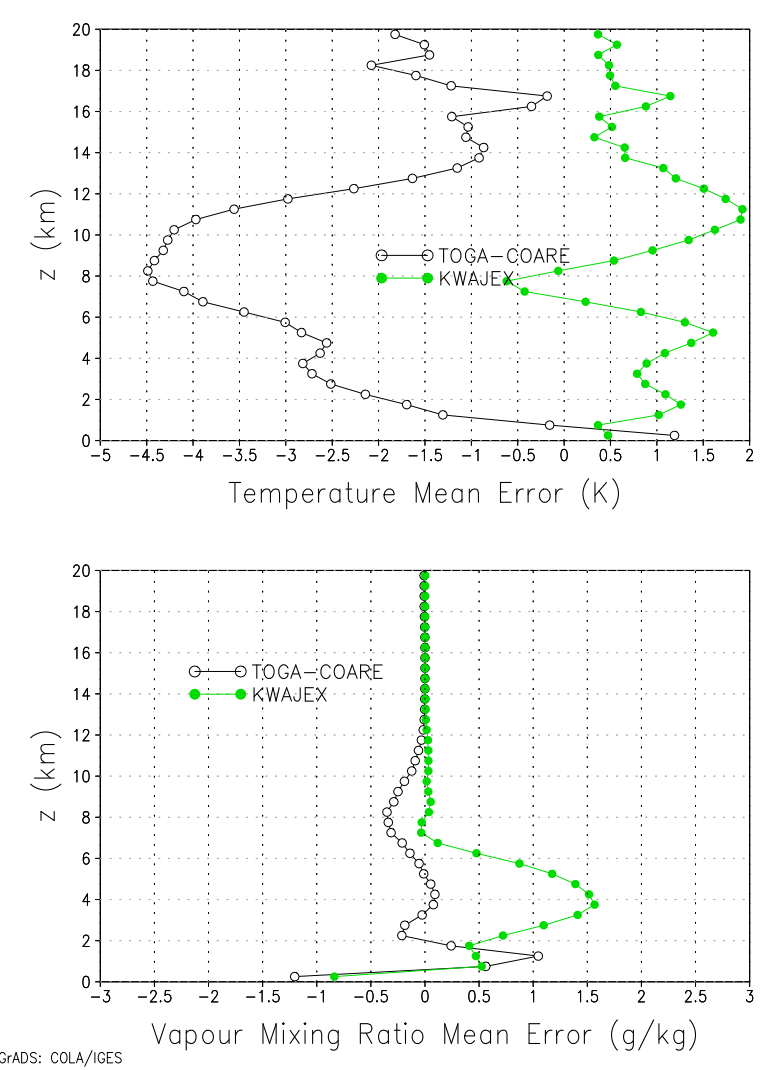

Fig. A3. Mean errors of temperature and vapour mixing ratio for both oceanic cases, unconditionally averaged as in Fig. 4.

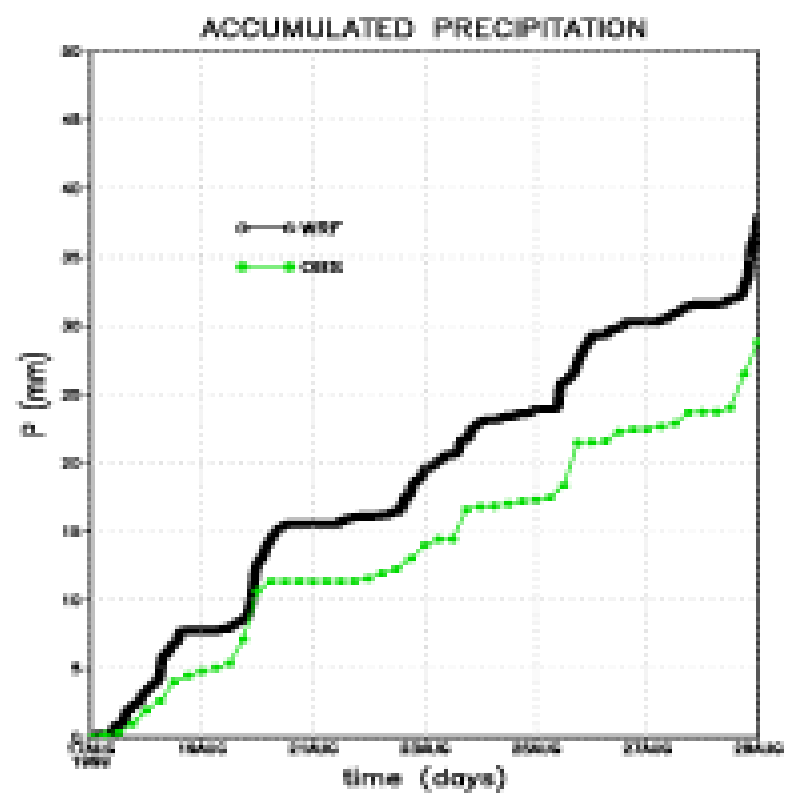

Fig. A4. Observed and predicted ("WRF") domain-wide accumulated surface precipitation throughout the entire simulated period of KWAJEX. 
The surface precipitation accumulated throughout KWAJEX is displayed in Fig. A4, from observations and the model. Relative errors in peak rates of predicted precipitation during almost all episodes of deep convection during KWAJEX and TOGA-COARE are less than about 50\%. All episodes of intense precipitation are reproduced.

Acknowledgement. The first and second authors were partially funded by an award (NNG05HL30i) from the National Aeronautics and Space Administration (NASA). The work done for the present study is applicable to the award, which concerns development of a cloud model to simulate impacts of insoluble aerosol on deep convection in the Tropical Cloud Systems and Processes (TCSP) project. Support for C. McNaughton was provided through NASA's Earth System Science Fellowship, NNG-05-GQ-45H. Statements, findings, conclusions, and recommendations are those of the authors and do not necessarily reflect the views of NASA. The work was also partially funded by awards from the National Science Foundation (ATM-0427128) and the National Oceanic and Atmospheric Administration/Climate Prediction Program for the Americas (NA07OAR4310257). The authors are grateful to Greg McFarquhar, Jeff Stith and Bob Dattore for the valuable data they provided. The authors would like to thank Antony Clarke for providing the INTEX-NA aerosol data via NASA grant NNG-04GB-39G. The authors are grateful to Paul DeMott, Steve Howell, Ruprecht Jaenicke and Russell Schnell for their constructive advice, and to the three anonymous reviewers.

Edited by: A. Arneth

\section{References}

Albrecht, B.: Aerosols, cloud microphysics, and fractional cloudiness, Science, 245, 1227-1230, 1989.

Blyth, A. M. and Latham, J.: Development of ice and precipitation in New Mexican summertime cumulus clouds, Q. J. Roy. Meteorol. Soc., 119, 91-120, 1993.

Blyth, A. M., Benestad, R. E., Krehbiel, P. R., and Latham, J.: Observations of supercooled raindrops in New Mexico summertime cumuli, J. Atmos. Sci., 54, 569-575, 1997.

Burks, J. E.: Radiative fluxes and heating rates during TOGACOARE over the Intensive Flux Array, MSc dissertation, University of Utah, 1998.

Caristi, J., Sands, D. C., and D. G. Georgakopoulos: Simulation of epiphytic bacterial growth under field conditions, Simulation, 56, 295-301, 1991.

Christner, B. C., Morris C. E., Foreman C. M., Cai, R., and D. C. Sands: Ubiquity of biological ice nucleators in snowfall, Science, 319, 5867, p. 1214, 2008.

Christner, B. C., Cai, R., Morris C. E., McCarter, K. S., Foreman, C. M., Skidmore, M. L., Montross, S. N., and D. C. Sands: Geographic, seasonal, and precipitation chemistry influence on the abundance and activity of biological ice nucleators in rain and snow. PNAS, 105(48), 18854-18859, 2008

Ciesielski, P. E., Hartten, L. M., and Johnson, R. H.: Impacts of merging profiler and rawinsonde wins on TOGA-COARE analyses, J. Atmos. Ocean. Tech., 14, 1264-1279, 1997.
Clarke, A. D. and Kapustin, V.: A Pacific aerosol survey. Part I: A decade of data on particle production, transport, evolution, and mixing in the troposphere, J. Atmos. Sci., 59, 363-382, 2002.

Clarke, A. D. and Porter, J. N.: Pacific marine aerosol 2. Equatorial gradients in chlorophyll, ammonium, and excess sulfate during SAGA 3, J. Geophys. Res., 98(D9), 16997-17010, 1993.

Clarke, A. D., McNaughton, C. M., Kapustin, V., Shinozuka, Y., Howell, S., Dibb, J., Zhou, J., Anderson, B., Brekhovskikh, V., Turner, H., and Pinkerton, M.: Biomass burning and pollution aerosol over North America: organic components and their influence on spectral optical properties and humidification response, J. Geophys. Res., 112, D12S18, doi:10.1029/2006JD007777, 2007.

Clarke, A. D., Owens, S. R., and Zhou, J.: An ultrafine sea-salt flux from breaking waves: Implications for cloud condensation nuclei in the remote marine atmosphere, J. Geophys. Res., 111, D06202, doi:10.1029/2005JD006565, 2006.

Clarke, A. D., Shinozuka, Y., Kapustin, V. N., Howell, S., Huebert, B., Doherty, S., Anderson, T., Covert, D., Anderson, J., Hua, X., Moore, K. G. II, McNaughton, C., Carmichael, G., and Weber, R.: Size distributions and mixtures of dust and black carbon aerosol in Asian outflow: Physiochemistry and optical properties, J. Geophys. Res., 109, D15S09, doi:10.1029/2003JD004378, 2004.

Cziczo, D. J., Murphy, D. M., Hudson, P. K., and Thomson, D. S.: Single particle measurements of the chemical composition of cirrus ice residue during CRYSTAL-FACE, J. Geophys. Res., 109(D4), D04201, doi:10.1029/2003JD004032, 2004.

DeMott, P. J., Cziczo, D. J., Prenni, A. J., Murphy, D. M., Kreidenweis, S. M., Thomson, D. S., Borys, R., and Rogers, D. C.: Measurements of the concentration andcomposition of nuclei for cirrus formation., P. Natl. Soc. Sci., 100, 14655-14660, 2003a.

DeMott, P. J., Sassen, K., Poellot, M. R., Baumgardner, D., Rogers, D. C., Brooks, S. D., Prenni, A. J., and S. M. Kreidenweis: African dust aerosols as atmospheric ice nuclei, Geophys. Res. Lett., 30(14), 1732, doi:10.1029/2003GL017410, 2003b.

Després, V. R., Nowoisky, J. F., Klose, M., Conrad, R., Andreae, M. O., and Pöschl, U.: Characterization of primary biogenic aerosol particles in urban, rural, and high-alpine air by DNA sequence and restriction fragment analysis of ribosomal RNA genes, Biogeosciences, 4, 1127-1141, 2007, http://www.biogeosciences.net/4/1127/2007/.

Diehl, K., Quick, C., Matthias-Maser, S., Mitra, S. K., and Jaenicke, R.: The ice nucleating ability of pollen. Part I: Laboratory studies in deposition and condensation freezing modes, Atmos. Res., 58, 75-87, 2001

Diehl, K. and Wurzler, S.: Heterogeneous drop freezing in the immersion mode: model calculations considering soluble and insoluble particles in the drops, J. Atmos. Sci., 61, 2063-2071, 2004.

Diehl, K., Simmel, M., and Wurzler, S.: Numerical sensitivity studies on the impact of aerosol properties and drop freezing modes on the glaciation, microphysics, and dynamics of clouds, J. Geophys. Res., 111, 7202, doi:10.1029/2005JD005884, 2006.

Eidhammer, T., DeMott, P. J., and Kreidenweis, S. M.: A comparison of heterogeneous ice nucleation parameterizations using a parcel model framework, J. Geophys. Res., 114, D06202, doi:10.1029/2008JD011095, 2009.

Feingold, G., Cotton, W. R., Kreidenweis, S. M., and Davis, J. T.: Impact of giant cloud condensation nuclei on drizzle formation 
in marine stratocumulus: Implications for cloud radiative properties, J. Atmos. Sci., 56, 4100-4117, 1999.

Flossmann, A. I. and Pruppacher, H. R.: A theoretical study of the wet removal of atmospheric pollutants. Part III: the uptake, redistribution, and deposition of (NH4)2SO4 particles by a convective cloud using a two-dimensional cloud dynamics model, J. Atmos. Sci., 45, 1857-1871, 1988.

Forster, P., Ramaswamy, V., Artaxo, P., Berntsen, T., Betts, R., Fahey, D. W., Haywood, J., Lean, J., Lowe, D. C., Myhre, G., Nganga, J., Prinn, R., Raga, G., Schulz, M., and Van Dorland, R.: Changes in Atmospheric Constituents and in Radiative Forcing, in: Climate Change 2007: The Physical Science Basis. Contribution of Working Group I to the Fourth Assessment Report of the Intergovernmental Panel on Climate Change, edited by: Solomon, S., Qin, D., Manning, M., Chen, Z., Marquis, M., Averyt, K. B.,Tignor, M., and Miller, H. L., Cambridge University Press, Cambridge, United Kingdom and New York, NY, USA, 2007.

Geophysical Fluid Dynamics Laboratory (GFDL) Global Atmospheric Model Development Team (GAMDT): The new Geophysical Fluid Dynamics Laboratory (GFDL) global atmosphere and land model AM2/LM2: Evaluation with prescribed SST simulations, J. Climate, 17(24), 4641-4673, 2004.

Ghan, S., Randall, D., Xu, K.-M., Cederwall, R. T., Cripe, D. G., Hack, J., Iacobellis, S. F., Klein, S. A., Krueger, S. K., Lohmann, U., Pedretti, J., Robock, A., Rotstayn, L. D., Sommerville, R. C., Stenchikov, G., Sud, Y. C., Walker, G. K., Xie, S. C., Yio, J. J., and Zhang, M.-H.: A comparison of single column model simulations of summertime midlatitude continental convection, J. Geophys. Res., 105, 2091-2124, 2000.

Gross, D. C., Cody, Y. S., Proebsting, E. L., Radamaker, G. K., and R. A. Spotts: Distribution, population dynamics, and characteristics of ice nucleation-active bacteria in deciduous fruit tree orchards, Appl. Environ. Microbiol., 46(6), 1370-1379, 1983.

Hallett, J. and Mossop, S. C.: Production of secondary ice particles during the riming process, Nature, 249, 26-28, 1974.

Harris-Hobbs, R. L. and Cooper, W. A.: Field evidence supporting quantitative predictions of secondary ice production rates, J. Atmos. Sci., 44, 1071-1082, 1987.

Harrison, R. M., Jones, A. M., Biggins, P. D., Pomeroy, N., Cox, C. S., Kidd, S. P., Hobman, J. L., Brown, N. L., and Beswick, A.: Climate factors influencing bacterial count in background air samples, Int. J. Biometeorol., 49(3), 167-178, 2005.

Heymsfield, A. J., Lewis, S., Bansemer, A., Iaquinta, J., and Miloshevich, L. M.: A general approach for deriving the properties of cirrus and stratiform ice cloud particles, J. Atmos. Sci., 59, 3-29, 2002a.

Heymsfield, A. J., Bansemer, A., Field, P. R., Durden, S. L., Stith, J. L., Dye, J. E., Hall, W., and Grainger, C.: Observations and parameterizations of particle size distributions in deep tropical cirrus and stratiform precipitating clouds: results from in situ observations in TRMM field campaigns, J. Atmos. Sci., 59, 34573491, 2002b.

Heymsfield, A. J., Miloshevich, L. M., Schmitt, C., Bansemer, A., Twohy, C., Poellot, M. R., Fridlind, A., and Gerber, H.: Homogeneous ice nucleation in subtropical and tropical convection and its influence on cirrus anvil microphysics, J. Atmos. Sci., 62, 41-65, 2005.

Hirano, S. S., Baker, L. S., and C. D. Upper: Ice nucleation tem- perature of individual leaves in relation to population sizes of ice nucleation active bacteria and frost injury, Plant Physiol., 77(2), 259-265, 1985.

Hobbs, P. V., Bowdle, D. A., and Radke, L. F.: Particles in the lower troposphere over the High Plains of the United States. II: Cloud condensation nuclei, J. Clim. Appl. Meteorol., 24, 1358-1369, 1985.

Horowitz, L. W.: Past, present, and future concentrations of tropospheric ozone and aerosols: Methodology, ozone evaluation, and sensitivity to aerosol wet removal, J. Geophys. Res., 111, D22211, doi:10.1029/2005JD006937, 2006.

Jaenicke, R.: Abundance of cellular material and proteins in the atmosphere, Science, 308(5718), p. 73, 2005.

Khain, A., Pokrovsky, A., Pinsky, M., Seifert, A., and Phillips, V. T. J.: Simulation of effects of atmospheric aerosols on deep turbulent convective clouds by using a spectral microphysics mixedphase cumulus cloud model. Part 1: Model description and possible applications, J. Atmos. Sci., 61(24), 2963-2982, 2004.

Khain, A. and Pokrovsky, A.: Simulation of effects of atmospheric aerosols on deep turbulent convective clouds by using a spectral microphysics mixed-phase cumulus cloud model. Part II: Sensitivity study, J. Atmos. Sci., 61(24), 2983-3001, 2004.

Khairoutdinov, M. and Kogan, Y.: A new cloud physics parameterization in a large-eddy simulation model of marine stratocumulus, Mon. Weather Rev., 128, 229-243, 2000.

Khairoutdinov, M. F. and Randall, D. A.: Cloud resolving modeling of the ARM summer 1997 IOP: model formulation, results, uncertainties, and sensitivities, J. Atmos. Sci., 60, 607-625, 2003.

Koop, T., Luo, B. P., Tsias, A., and Peter, T.: Water activity as the determinant for homogeneous ice nucleation in aqueous solutions, Nature, 406, 611-614, 2000.

Lee, S. S., Donner, L. J., Phillips, V. T. J., and Ming, Y.: Examination of aerosol effects on precipitation in deep convective clouds during the 1997 ARM summer experiment, Q. J. Roy. Meteorol. Soc., 634, 1201-1220, 2008.

Levin, Z. and Yankofsky, S. A.: Contact versus immersion freezing of freely suspended droplets by bacterial ice nuclei, J. Clim. Appl. Meteorol., 22(11), 1964-1966, 1983.

Liljegren, J. C.: Two-channel microwave radiometer for observations of total column precipitable water vapor and cloud liquid water path. Proceedings of the Fifth Symposium on Global Change, 23-28 January, 1994, Nashville, TN, Amer. Meteor. Soc., Boston, MA, 266-269, 1994.

Lindemann, J., Constantinidou, H. A., Barchet, W. R., and Upper, C. D.: Plants as sources of airborne bacteria, including ice nucleation-active bacteria, Appl. Environ. Microb., 44(5), 10591063, 1982.

Lindow, S. E., Arny, D. C., and Upper, C. D.: Distribution of ice nucleation-active bacteria on plants in nature, Appl. Environ. Microb., 36(6), 831-838, 1978.

Lindow, S. E.: Population dynamics of epiphytic ice nucleation active bacteria on frost sensitive plants and frost control by means of antagonistic bacteria. Plant Cold-Hardiness and Freezing Stress, Vol. 2, edited by: Li, P. H. and Sakai, A., Academic Press, 395-416, 1982.

Lindow, S. E., Arny, D. C., and Upper, C. D.: Bacterial ice nucleation: A factor in frost injury to plants, Plant Physiol., 70, 1084-1089, 1982.

Lindow, S. E., Lahue, E., Govindarajan, A. G., Panopoulos, N. 
J., and Gies, D.: Localization of ice nucleation activity and the iceC gene product in Pseudomonas syringae and Escherichia coli, Mol. Plant Microbe. In., 2(5), 262-272, 1989.

Lohmann, U., Feichter, J., Chuang, C., and Pennner, J. E.: Predicting the number of cloud droplets in the ECHAM GCM, J. Geophys. Res., 104, 9169-9198, 1999.

Lohmann, U. and Feichter, J.: Global indirect aerosol effects: a review, Atmos. Chem. Phys., 5, 715-737, 2005, http://www.atmos-chem-phys.net/5/715/2005/.

Maki, L. R., Galyan, E. L., Chang-Chien, M. M., and Caldwell, D. R.: Ice nucleation induced by Pseudomonas Syringae, Appl. Environ. Microb., 28(3), 456-459, 1974.

Matthias-Maser, S. and Jaenicke, R.: the size distribution of primary biological aerosol particles with radii $>0.2 \mu \mathrm{m}$ in an urban/rural influenced region, Atmos. Res., 39(4), 279-286, 1995.

McFarquhar, G. M., Heymsfield, A. J., Macke, A., Iaquinta, J., and Aulenbach, S. M.: Use of observed ice crystal sizes and shapes to calculate mean-scattering properties and multispectral radiances: CEPEX April 4, 1993, case study, J. Geophys. Res., 104(D24), 31763-31779, 1999.

McNaughton, C.: Constraining climate model simulations of aerosol size distributions over the North Pacific and North America using in-situ airborne measurements $\mathrm{PhD}$ thesis, University of Hawaii at Manoa, Honolulu, USA, 2008.

Ming, Y., Ramaswamy, V., Donner, L. J., and Phillips, V. T. J.: A new parameterization of cloud droplet activation applicable to general circulation models., J. Atmos. Sci., 63, 1348-1356, 2006.

Ming, Y., Ramaswamy, V., Donner, L. J., Phillips, V. T. J., Klein, S. A., Ginoux, P. A., and Horowitz, L. H.: Modeling the interactions between aerosols and liquid water cloud with a self-consistent cloud scheme in a general circulation model, J. Atmos. Sci., 64, 1189-1209, 2007.

Minnis, P., Smith, W. L., Garber, D. P., Ayers, J. K., and Doelling, D. R.: Cloud properties derived from GOES-7 for spring 1994 ARM intensive observation period using version 1.0.0 of ARM satellite data analysis program,, NASA reference publication 1366, 1995.

Möhler, O., DeMott, P. J., Vali, G., and Levin, Z.: Microbiology and atmospheric processes: the role of biological particles in cloud physics, Biogeosciences, 4, 1059-1071, 2007, http://www.biogeosciences.net/4/1059/2007/.

Morris, C. E., Georgakopoulos, D. G., and Sands, D. C.: Ice nucleation active bacteria and their potential role in precipitation, J. Phys. IV France, 121, 87-103, 2004.

Morris, C. E., Sands, D. C., Vinatzer, B. A., Glaux, C., Guilbaud, C., Buffiére, A., Yan, S., Dominguez, H., and Thompson, B.: The life history of the plant pathogen Pseudomonas syringae is linked to the water cycle, ISME Journal, 2, 321-334, doi:10.1038/ismej.2007.113, 2008a.

Morris, C. E., Sands, D. C., Bardin, M., Jaenicke, R., Vogel, B., Leyronas, C., Ariya, P. A., and Psenner, R.: Microbiology and atmospheric processes: an upcoming era of research on biometeorology, Biogeosciences Discuss., 5, 191-212, 2008b,

http://www.biogeosciences-discuss.net/5/191/2008/.

Morrison, H., Curry, J. A., and Khvorostyanov, V. I.: A new doublemoment microphysics parameterization for applicationa in cloud and climate models. Part I: Description, J. Atmos. Sci., 62, 16651677, 2005.

Pawlowska, H. and Brenguier, J. L.: The indirect effect of aerosol on climate: effect of aerosol properties on precipitation efficiency, 856-859 in Proceedings of the 13th International Conference on Clouds and Precipitation, held at Reno, Nevada, 2000.

Petters, M. D. and Kreidenweis, S. M.: A single parameter representation of hygroscopic growth and cloud condensation nucleus activity, Atmos. Chem. Phys., 7, 1961-1971, 2007, http://www.atmos-chem-phys.net/7/1961/2007/.

Phillips, V. T. J., Blyth, A. M., Choularton, T. W., Brown, P. R. A., and Latham, J.: The glaciation of a cumulus cloud over New Mexico, Q. J. Roy. Meteorol. Soc., 127, 1513-1534, 2001.

Phillips, V. T. J., Choularton, T. W., Blyth, A. M., and Latham, J.: The influence of aerosol concentrations on the glaciation and precipitation production of a cumulus cloud, Q. J. Roy. Meteorol. Soc., 128, 951-971, 2002.

Phillips, V. T. J., Choularton, T. W., Illingworth, A. J., Hogan, R. J., and Field, P. R.: Simulations of the glaciation of a frontal mixedphase cloud with the Explicit Microphysics Model (EMM), Q. J. Roy. Meteorol. Soc., 129, 1351-1371, 2003.

Phillips, V. T. J., Sherwood, S. C., Andronache, C., Bansemer, A., Conant, W. C., DeMott, P. J., Flagan, R. C., Heymsfield, A., Jonsson, H., Poellot, M., Rissman, T. A., Seinfeld, J. H., Vanreken, T., Varutbangkul, V., and Wilson, J. C.: Anvil glaciation in a deep cumulus updraft over Florida simulated with an Explicit Microphysics Model. I: The impact of various nucleation processes, Q. J. Roy. Meteorol. Soc., 131, 2019-2046, 2005.

Phillips, V. T. J. and Donner, L. J.: Cloud microphysics, radiation and vertical velocities in two- and three-dimensional simulations of deep convection, Q. J. Roy. Meteorol. Soc., 132, 3011-3033, 2006.

Phillips, V. T. J., Donner, L. J., and Garner, S.: Nucleation processes in deep convection simulated by a cloud-system resolving model with double-moment bulk microphysics, J. Atmos. Sci., 64, 738761, 2007.

Phillips, V. T. J., DeMott, P. J., and Andronache, C.: An empirical parameterization of heterogeneous ice nucleation for multiple chemical species of aerosol, J. Atmos. Sci., 65, 2757-2783, 2008.

Pratt, K. A., DeMott, P. J., French, J. R., Wang, Z., Westphal, D. L.,Heymsfield, A. J., Twohy, C. H., Prenni, A. J., and Prather, K. A.: In situ detection of biological particles in cloud ice-crystals, Nature Geoscience, doi:10.1038/ngeo521, 2009.

Pruppacher, H. R. and Klett, J. D.: Microphysics of clouds and precipitation, Kluwer Academic Publishers, 1997.

Rossow, W. B. and Zhang, Y.-C.: Calculation of surface and top of atmosphere radiative fluxes from physical quantities based on ISCCP datasets. 2. Validation and first results, J. Geophys. Res., 100, 1167-1197, 1995.

Salzmann, M., Lawrence, M. G., Phillips, V. T. J., and Donner, L. J.: Model sensitivity studies regarding the role of the retention coefficient for the scavenging and redistribution of highly soluble trace gases by deep convective cloud systems, Atmos. Chem. Phys., 7, 2027-2045, 2007, http://www.atmos-chem-phys.net/7/2027/2007/.

Sands, D. C., Langhans, V. E., Scharen, A. L., and G. deSmet: The association between bacteria and rain and possible resultant meteorological implications, J. Hungarian Meterol. Serv., 86, 148$152,1982$.

Schnell, R. C. and Vali, G.: Atmospheric ice nuclei from decomposing vegetation, Nature, 236, 163-165, 1972. 
Schnell, R. C. and Vali, G.: Biogenic ice nuclei. I - Terrestrial and marine sources, J. Atmos. Sci., 33, 1554-1564, 1976.

Sheridan, P. J., Delene, D. J., and Ogren, J. A.: Four years of continuous surface aerosol measurements from the Department of Energy's Atmospheric Radiation Measurement Program Southern Great Plains Cloud and Radiation Testbed site, J. Geophys. Res., 106(D18), 20735-20747, 2001.

Targino, A. C., Krejci, R., Noone, K. J., and Glantz, P.: Single particle analysis of ice crystal residuals observed in orographic wave clouds over Scandinavia during INTACC experiment, Atmos. Chem. Phys., 6, 1977-1990, 2006,

http://www.atmos-chem-phys.net/6/1977/2006/.

Thompson, G., Rasmussen, R. M., and Manning, K.: Explicit forecasts of winter precipitation using an improved bulk microphysics scheme. Part I: description and sensitivity analysis, Mon. Weather Rev., 132, 519-542, 2004.

Twomey, S. A.: The nuclei of natural cloud formation. Part II: The supersaturation in natural clouds and the variation of cloud droplet concentrations, Geofis. Pure Appl., 43, 227-242, 1959.

Twomey, S. A.: The influence of pollution on the shortwave albedo of clouds, J. Atmos. Sci., 34, 1149-1152, 1977.

Vali, G., Chistensen, M., Fresh, R. W., Galyan, E. L., Maki, L. R., and Schnell, R. C.: Biogenic ice nuclei. II - Bacterial sources, J. Atmos. Sci., 33, 1565-1570, 1976.

Weller, R. A. and Anderson, S. P.: Surface meteorology and airsea fluxes in the western equatorial Pacific warm pool during the TOGA Coupled Ocean-Atmosphere Response Experiment, J. Climate, 9, 1959-1990, 1996.

Xie, S., Xu, K.-M., Cederwall, R. T., Bechtold, P., Del Genio, A. D., Klein, S. A., Cripe, D. G., Ghan, S. J., Gregory, D., Iacobellis, S. F., Krueger, S. K., Lohmann, U., Petch, J. C., Rotstayn, L. D., Randall, D. A., Sommerville, R. C., Sud, Y. C., Salzen, K., Walker, G. K., Wolf, A., Yio, J. J., Zhang, G. J., and Zhang, M.H.: Intercomparison and evaluation of cumulus parametrizations under summertime midlatitude continental conditions, Q. J. Roy. Meteorol. Soc., 128, 1095-1135, 2002.

Xu, K.-M., Cederwall, R. T., Donner, L. J., Grabowski, W. W., Guichard, F., Johnson, D. E., Khairoutdinov, M., Krueger, S. K., Petch, J. C., Randall, D. A., Seman, C. J., Tao, W.-K.,Wang, D., Xie, S. C., Yio, J. J., and Zhang, M.-H.: An intercomparison of cloud-resolving models with the Atmospheric Radiation Measurement summer 1997 intensive observations period data, Q. J. Roy. Meteorol. Soc., 128, 593-624, 2002.

Zhang, M. H, Lin, J. L., Cederwall, R. R., Yio, J. J., and Xie, S. C.: Objective analysis of ARM IOP data: Method and sensitivity, Mon. Weather Rev., 129, 295-311, 2001.

Zhang, Y.-C., Rossow, W. B., and Lacis, A. A.: Calculation of surface and top of atmosphere radiative fluxes from physical quantities based on ISCCP datasets. 1. Method and sensitivity to input data uncertainties, J. Geophys. Res., 100, 1149-1166, 1995.

\section{Note added in proof}

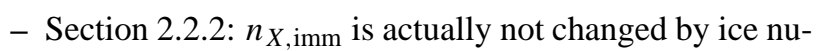
cleation, and is hypothetical in this sense. Also, everywhere outside clouds, $n_{X, a, \mathrm{imm}}=n_{X, a}=n_{X, \mathrm{imm}}=0$.

- Section 2.2.3: Activation of cloud-liquid involves incrementing $n_{X, a \text {,imm }}$ and $n_{X \text {,imm }}$ by the number of clouddroplets formed by species $X$. During heterogeneous ice nucleation, $n_{X \text {,imm }}$ is not changed because the surface area of aerosols used by the empirical parameterization is unchanged by ice nucleation, being hypothetical in this sense.

Aerosol mass mixing ratios contained in cloud $\left(Q_{X \text {,cld }}\right)$ and precipitation $\left(Q_{X, \text { prec }}\right)$ are both unchanged by freezing or melting. When clear air becomes cloudy, $Q_{X \text {,cld }}$ is incremented by the same amount that $Q_{X \text {, air }}$ is reduced by.

During homogeneous freezing of cloud-liquid, $n_{X \text {,imm }}$ is actually unchanged. During homogeneous freezing of soluble aerosols, then $n_{X, a, \text { imm }}$ is increased by the number of aerosols frozen each time-step.

During partial evaporation of cloud-liquid, $n_{X, a, \mathrm{imm}}$ is reduced by the ratio of the number of droplets lost to the sum of $n_{X, a, i m m}$ in all 6 species, in addition to the re-

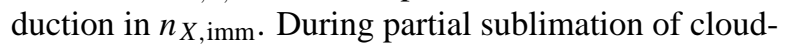
ice, in addition to reducing $n_{X, \text { imm }}$ and $n_{X, a, \text { imm }}$ (inferred from the fraction of crystals nucleated heterogeneously), also $n_{X, a}$ is depleted by the fraction of the crystal number sublimed away during the time-step. No such changes are done during evaporation of precipitation,. Finally, when cloud totally evaporates away, $n_{X, a, \mathrm{imm}}, n_{X, a}$ and $n_{X, \mathrm{imm}}$ are all set to zero.

Concerning scavenging of aerosols by precipitation, $n_{X, a}$ and $n_{X, a, \text { imm }}$ are actually both unchanged by this process. 